Article

\title{
A Comparative Study on Sustainability in Architectural Education in Asia-With a Focus on Professional Degree Curricula
}

\author{
Santiago Porras Álvarez ${ }^{1, *}$, Kyungsun Lee ${ }^{2, *}$, Jiyoung Park ${ }^{3, *}$ and Sun-Young Rieh ${ }^{4}$ \\ 1 Department of Architecture, Korea University, 145 Anam-ro, Seongbuk-gu, Seoul 02481, Korea \\ 2 School of Architecture, Hongik University, 94 Wausan-ro, Mapo-gu, Seoul 04066, Korea \\ 3 Department of Architecture, Inha University, 100 Inha-ro, Nam-gu, Incheon 22212, Korea \\ 4 Department of Architecture, University of Seoul, 163 Seoulsiripdae-ro, Dongdaemun-gu, Seoul 02504, Korea; \\ syrieh@uos.ac.kr \\ * Correspondence: santiago@korea.ac.kr (S.P.Á.); ksunlee@hongik.ac.kr (K.L.); jypark@inha.ac.kr (J.P.); \\ Tel.: +82-10-8966-5561 (S.P.Á.); +82-10-3731-2170 (K.L.); +82-10-7395-7115 (J.P.)
}

Academic Editor: Thorsten Schuetze

Received: 30 November 2015; Accepted: 15 March 2016; Published: 22 March 2016

\begin{abstract}
Architectural education is a key factor in the re-thinking of the whole industry toward a system of more sustainable buildings and cities. Asia is the continent with the highest population growth and the fastest urbanization rate on earth. It is necessary to educate professionals with a well-balanced and integrated knowledge of local issues and global standards. This paper focuses on education for sustainable architecture in Asian countries. This is an exploratory study, analyzing the curricula of 20 selected influential schools in 11 countries. Sustainability-related courses are identified, classified and summarized in qualitative tables (course matrix) and in quantitative graphs. The analysis helps to identify trends and regional or individual uniqueness. The results show that sustainability education is organized in very diverse ways, according to contents, intensity and sequence. The percentages of sustainable courses range from less than $5 \%$ to $25 \%$. Technology-related courses are the most numerous and homogeneous. Sustainability design studios show the greatest variation, from zero to almost $100 \%$. General theory courses help in dealing with sustainability issues through traditional and vernacular philosophies, technologies and strategies that are very adequate to their geographical and cultural settings.
\end{abstract}

Keywords: architectural sustainable curriculum; professional degree in architecture; locality; local urban cultures; Asian countries

\section{Introduction}

\subsection{Motivation}

Asia is the largest and most populated continent on Earth, showing the highest growth rates in terms of population and urbanization. It has been noted that Asia's population growth in the 20th century has almost increased four times, and based on current estimates, it is projected that national populations will grow until 2050 in most Asian countries [1]. After World War II the independence of the old colonies marked the start of a rapid economic development and urbanization movement. This continued process of rapid development threatens the continent's resources, habitats, and ecological-biological variety [2]. The industrialization and growth of information technology, services, and tourism industries have brought a rapid transformation of the traditional society. Poor planning policies, rapid urban growth, traffic and infrastructure network inconsistency, and pollution have caused health and social cohesion problems [3]. Asia is a diverse continent in terms of geographic 
characteristics and natural resources, and its development and urbanization trends are also changing, depending on country and region [1]. For example, East and Southeast Asian cities differ from those of India and China in terms of density and compactness [4].

Following the footsteps of the United Nations Environment Program (UNEP) at the World Wide Fund for Nature (WWF), from 1980 a large number of organizations and institutions are working to promote environmental awareness and means for a sustainable future. Among these, education is of utmost importance for achieving sustainable development [3]. The Brundtland Report [5] was the first step, after which the proceedings of the 1992 Earth Summit in Rio de Janeiro [6] were published, ending with the signature of Agenda 21 by participating countries, as a commitment to promote sustainability in all spheres of life including education and awareness [7]. At the Copenhagen 2009 conference on climate change, the Fifteenth session of the Conference of the Parties (COP15) stressed the urgency of taking measures to limit climate change and improve sustainability [8]. Among them, Education for Sustainable Development (ESD) is a key action [9].

Architecture has an essential role in sustainable development, and it is necessary to educate professionals who have a well-balanced and integrated knowledge of local issues and global standards. In order to achieve that, an appropriate implementation of sustainable architectural education curricula is needed in the schools. In this sense, the three pillars of sustainability, Environment, Society and Economy, are basic themes in elaborating the courses contents. In the field of architecture, the task is to find a way to provide the necessary knowledge and integrate design methodologies with tools and technologies to empower professionals to deal with the current and future environmental issues [10]. Current building regulations in Asian countries consider green architecture guidelines, but long-term sustainable design processes are still lacking [11]. Architects receive training in hundreds of schools spread all over the world, but the practice is regulated by national or local bodies, and sometimes license or accreditations are provided after the basic degree in some countries [12]. Architectural accreditation in Asia has two important international precedents; one is the USA's standard National Architectural Accrediting Board (NAAB) [13], which sets the basic requirements of professional educational programs including required sustainable contents. The other is the Royal British Institute of Architects (RIBA), still present in some former colonies and current Commonwealth countries, summarizing its vision in the famous "champion for architecture and for a better environment" [14]. Most Asian countries have accreditation agencies that in similar or diverse ways define the minimum skills and understanding related to sustainability to be provided by architecture educational curricula, and in general they are generic enough for the schools to develop them in their own ways. A review of the design and implementation of sustainable curricula in different schools and different Asian countries, along with unique features, similarities and disparities is hence of great interest to understand their degree of commitment towards ESD.

\subsection{Literature Review}

We did not find any wide international study in the East, Southeast and South Asian regions; however, a few papers attempted to systematize the comparative studies of university curricula at the national or regional level [15-18]. Salama and Amir surveyed a total of 18 schools of architecture in eight Arab countries [15]. Based on published literature review, they first studied the history of the regional development of architectural education, and second, each school's philosophy, curricula and course offerings. Their purpose was to follow the introduction of sustainability and environmental consciousness among other new paradigmatic trends. The authors classified the non-traditional courses for each of these trends, and arranged a table listing all schools divided by countries and related courses. A rough estimation of the weight of each course (simply by the number of courses taught), and a survey of the faculty's level of awareness and importance given to these new trends completed the study. The authors identified a very irregular level of implementation, with only one of the 14 schools doing so in a balanced manner. Their most alarming finding was the lack of integration of these courses with the design studio, which was the backbone of all of the programs. 
Ostwald et al. [16] carried out a very extensive and complete survey of the 20 schools accredited by the Australasia Association of Schools of Architecture (AASA), 16 of them in Australia, three in New Zealand and one in Papua New Guinea [19]. The data were obtained through questionnaires, interviews and extensive literature reviews. For curricula, their methodology consisted of classifying all courses into seven categories (design, technology, history and theory, communication, practice, environment, and electives), and then comparing the relative weight of each category within the total, arranging the data in several charts in two different periods, 1994 and 2006, in order to identify significant trends. This method proved useful in pointing out trends in time and differences or common points between countries and schools. In the field of environment and sustainability, the very different way each school addressed it became a challenge, making findings difficult to interpret. They found some schools had over $15 \%$ of their curricula focused on environment, while in others it was apparently absent. This approach did not provide any specific detail on the environmental curriculum [16] (pp. 129-130). Altomonte et al. in the publication EDUCATE, State of the Art Academic Curricula and Conditions for Registration, carried out the most extensive survey we have found, centered on the implementation of sustainable education in the European schools after the Bologna unification process [17]. This was part of a large project carried between 2009 and 2012, with the cooperation of seven European universities in six countries, and over 60 teams of authors. The survey was based on a questionnaire which included a description of the environmental design courses and modules, and their degree of integration with the design studio in a total of 69 curricula. One interesting approach in their methodology was identifying environmental design and technology modules by real course names and their credits, along the general theoretical modules (either technology or history/theory) and the design studio. Since the schools were analyzed one by one, there was no need to refer to general abstract categories, as in the previous reference. Especially original is the classification of three degrees of integration for the environmental modules in the design studio: (a) satellite; (b) partly integrated; (c) integrated. However, the high level of detail was a drawback, as there is not a clear side by side comparison among the schools to provide a general overview. Lee et al. [18] carried out an extensive survey across 36 Korean schools, 30 of which were at the time accredited by the Korea Architectural Accrediting Board (KAAB). The purpose was to determine the extent of sustainability education in their programs. The data were obtained from faculty surveys and published university curricula. Among other findings, the study concluded the need for curricular improvements, especially better integration of theoretical sustainability courses in design studios. It also found a need for creating more awareness of the importance of sustainability issues among faculty and students.

Apart from the above examples of wide national and international surveys, there are several smaller and interesting case studies that address the problem of integrating sustainability modules into the design studio. Karol [20] presents a common problem, namely, the isolated character of the sustainability modules which do not find their way into the design studio process. A case study at Curtin University of Technology in Australia clearly exemplifies this. The school introduced a required course in 1999 on Ecologically Sustainable Design in the first year, with the intention of creating student awareness from the beginning. However, after seven years the author did not find any sustainable intent in their design work, and suggested ways to overcome this problem.

Knusdtrop et al. [21] in a similar way, presented a strategy developed at Aalborg University called the Integrated Design Process (IDP) as an alternative to the traditional design studio scheme, based on practical projects, in which from the starting moment reduced energy and limited $\mathrm{CO}_{2}$ emissions objectives were introduced along the remaining design concepts. However, this approach was more limited, as the social issues were secondary, and economic sustainability was not mentioned.

Malik and Rahman [10] also tried to overcome the isolation of sustainability modules by integrating them in a very structured way along the five year architectural program at Universiti Sains Malaya (USM). Two interesting proposals arose from this paper. Firstly, the sustainability courses are planned within a five-year context in a progressive sequence, following the Malaysian Green Building Index (GBI) assessment plan, to end in a fifth-year project integrating all environmental issues and 
techniques learned in a complete graduation project. Secondly, they tried to adapt their approach to the local culture and climate, in a comprehensive manner, beyond the common focus on only energy efficiency. The case studies introduced a clear culture and region specific approach. Tanuwidjaja and Leonardo [22] provided a very complete context of the unique geographic, social, and climatic conditions in Indonesia, which call for specific tailoring of sustainability education in architecture. They thus elaborated a complete table based on the three main sustainability areas (environmental, social, and economic), detailed in sub-areas, and expanding each of these in well-defined specific strategies. Unfortunately they did not develop a method to implement it in the curricula, although, through an example, they explain its value as a clear checklist to be used during the design process. A more universal approach to the same issue is proposed by Hamity and Wydler [23]. Their assessment tool tries to be both simple and comprehensive, so faculty and students can apply it effectively. It assesses the degree of implementation of sustainable issues in existing curricula, and is based on the Swiss schools Education for Sustainable Development (ESD). Called the Spider Diagram, it consists of a polar diagram with seven radii, representing seven assessment parameters, each one graded from zero to one. According to the authors, it proved very effective after real testing, discovering areas to improve and reinforce, as well as identifying sustainability issues not explicit in the syllabus, but already implemented in the courses. One additional advantage of its simple and clear character was a provision of a tool for easy comparison among courses.

\subsection{Objectives and Paper Outline}

From the literature review, the importance of architectural education leading to more sustainable cities and buildings is clear. Existing studies show the interest in multinational and multicenter comparative studies of architectural education curricula, as well as the inherent difficulties these studies encompass. Given the relevance of Asia in urbanization and construction activity, such a study can provide insights on the vision and commitment towards sustainable architecture in the region. The present work is exploratory, analyzing a selection of schools in a sample of representative countries, comparing them in regard of their methods and degrees of implementation of sustainability education. For such a study, it is necessary to delineate the geographical area. In the present research we limited it to the East, Southeast, and Central-South regions of Asia, an area very heterogeneous, but also sharing many environmental and cultural connections. The second necessary step is to define the scope of the research, and a curriculum analysis alone is complex enough to deserve special attention. This paper attempts to highlight educational trends and patterns in the region, as the first step for a better understanding of the problem, and to suggest further research directions.

The Methodology section discusses the criteria for countries and schools selection, and the methodology for the qualitative analysis (nature and contents of the courses), and the quantitative analysis (weight of sustainable education within the curricula), complemented by an analysis on how the courses develop over successive years and integrate with the practical design courses. The following section, Discussion and Findings, shows in detail the results of the curriculum analysis for each country's schools systems, discussing the findings of the comparative study. Given the large amount of data analyzed, a series of tables summarize them to provide a compact presentation in a more visual way. Finally, the Conclusions section connects the findings with the research intent, and suggests subsequent steps for this line of research.

\section{Methodology}

\subsection{Delimitation of the Research Subject}

This is an exploratory and preliminary study, which intends to identify regional patterns and trends in the implementation of sustainable education in the curricula of Architecture schools. The first step is to establish a clear delimitation of the area of study and criteria to select the schools to analyze. 


\subsubsection{Geographical Criteria}

As Asia is extremely large and diverse, while trying to be as comprehensive as possible, we limited ourselves to an area with variety but also some differentiation from the rest of the continent: the East, Southeast, and Central-South Asia regions. This area expands around three traditional super powers, with China in the center, India in the West and Japan in the East. We focus on the most influential countries in the region, by educational, cultural, or economic standards. Apart from the aforementioned three countries, Singapore and Hong Kong are well-recognized global educational hubs, while Malaysia, Thailand, Korea, and Taiwan are well established or rising regional educational hubs with first-class institutions [24]. To expand the scope, we added Indonesia and Philippines, not only because of their cultural uniqueness and relevance in population and economic terms, but also because of their growing academic weight as well. Although the limited number of samples is an obvious limitation of this research, and the advantage of adding countries such as Pakistan or Vietnam could be mentioned, within this geographical context the selected countries provide already quite a significant sample from which conclusions and further paths of research can be developed.

\subsubsection{Schools Selection Criteria: International/Regional Leadership, National Leadership}

Even with the delimitation of the geographical area to the 11 selected countries, there are hundreds of institutions from which to choose. Ideally, a very large sample should be studied. However, we do not intend to use a statistical approach, and radical inclusiveness is beyond the scope of the present study. Furthermore, limiting the number of samples to the most meaningful or influential schools allows for more detail than a large inclusive study. We selected a total of 20 schools belonging to leading universities in their respective countries, $70 \%$ of which have also clear international recognition. To be objective we adopted as a reference a widely used ranking system, the QS world universities ranking [25]. Even with its caveats and limitations, designing a ranking system was well beyond the scope of this paper, and for our purpose it proved useful, as it is the only widely used ranking system we found that offers a score for architecture programs in Asia [26] (pp. 39-47). An additional positive point is that this ranking takes in strong consideration the perception of relevance and prestige by peer institutions' faculty members [27]. All schools chosen are within the Asia top 25 programs for Architecture and the Built Environment, and/or among 15 top universities of their respective countries $[28,29]$. The list of the selected schools and basic data is shown in Table 1 . Table 2 lists their accreditation organizations, and Table 3 lists the different names of the professional degrees they grant.

Table 1. Synopsis of countries, schools, programs, rankings, degrees and accreditations.

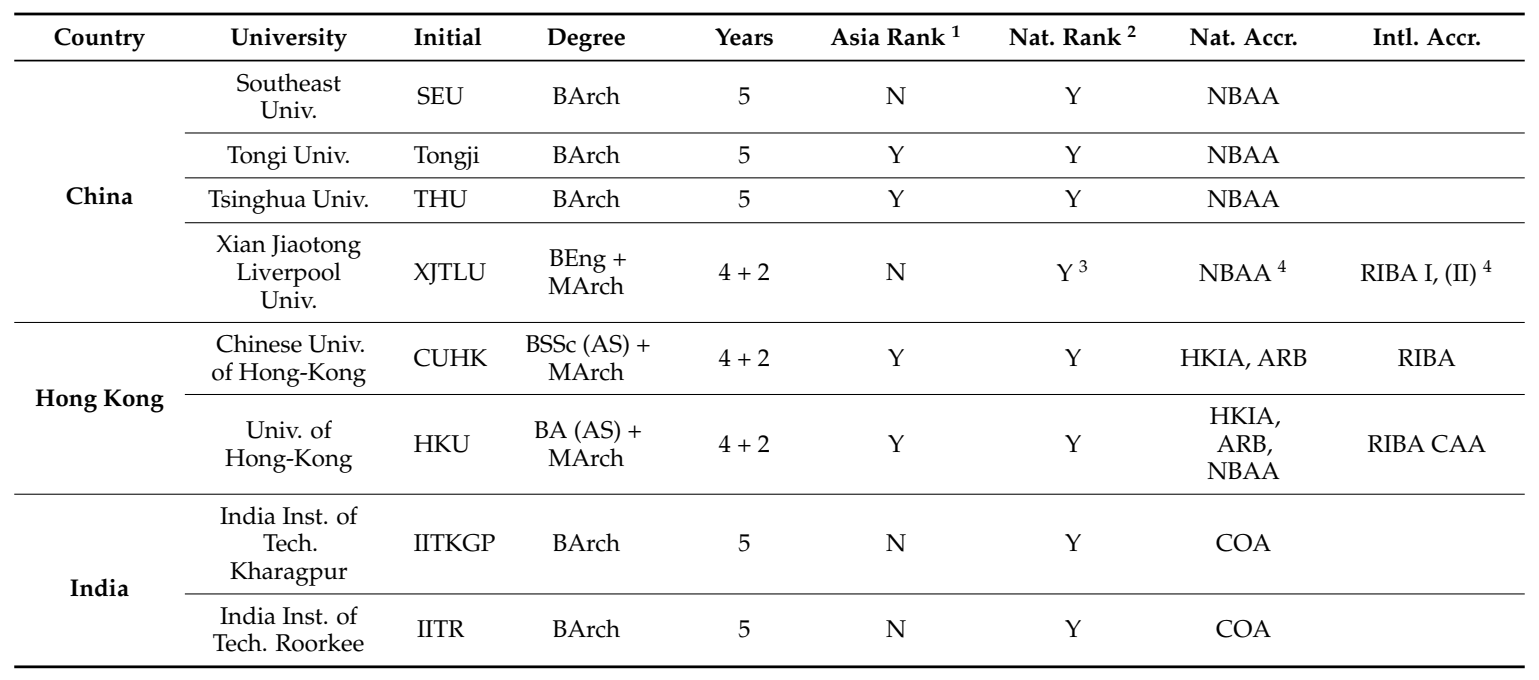


Table 1. Cont.

\begin{tabular}{|c|c|c|c|c|c|c|c|c|}
\hline Country & University & Initial & Degree & Years & Asia Rank ${ }^{1}$ & Nat. Rank ${ }^{2}$ & Nat. Accr. & Intl. Accr. \\
\hline Indonesia & $\begin{array}{l}\text { Institute of } \\
\text { Technology } \\
\text { Bandung }\end{array}$ & ITB & $\begin{array}{c}\text { BA }(\text { Arch })+ \\
\text { MArch }\end{array}$ & $4+1^{5}$ & $\mathrm{~N}$ & $\mathrm{Y}$ & IAI & $\mathrm{KAAB}^{6}$ \\
\hline \multirow{2}{*}{ Japan } & $\begin{array}{c}\text { Kyoto } \\
\text { University }\end{array}$ & Kyoto & BArch & 4 & $\mathrm{Y}$ & $\mathrm{Y}$ & $\mathrm{JABEE}^{7}$ & \\
\hline & $\begin{array}{c}\text { The } \\
\text { University of } \\
\text { Tokyo }\end{array}$ & UTokyo & BArch & 4 & Y & $\mathrm{Y}$ & JUAA $^{8}$ & \\
\hline \multirow{3}{*}{ Korea } & $\begin{array}{l}\text { Seoul } \\
\text { National } \\
\text { Univ. }\end{array}$ & SNU & BArch & 5 & Y & Y & KAAB & \\
\hline & $\begin{array}{l}\text { Sungkyunkwan } \\
\text { Univ. }\end{array}$ & SKKU & BArch & 5 & $\mathrm{Y}$ & $\mathrm{Y}$ & KAAB & \\
\hline & $\begin{array}{l}\text { University of } \\
\text { Seoul }\end{array}$ & UOS & BArch & 5 & $\mathrm{~N}$ & Y & KAAB & \\
\hline \multirow{2}{*}{ Malaysia } & $\begin{array}{c}\text { Universiti } \\
\text { Sans Malaysia }\end{array}$ & USM & $\begin{array}{c}\text { BsArch + } \\
\text { BArch }\end{array}$ & $3+2$ & $\mathrm{Y}$ & Y & LAM I, II & RICS \\
\hline & $\begin{array}{l}\text { Universiti } \\
\text { Teknologi } \\
\text { Malaysia }\end{array}$ & UTM & $\begin{array}{l}\text { BScArch + } \\
\text { MArch }\end{array}$ & $3+2$ & $\mathrm{~N}$ & Y & $\begin{array}{l}\text { LAM I, II, } \\
\text { PAM, JPA }\end{array}$ & \\
\hline Philippines & $\begin{array}{c}\text { University of } \\
\text { the } \\
\text { Philippines } \\
\text { Diliman }\end{array}$ & UPD & MsArch & 5 & $\mathrm{~N}$ & $\mathrm{Y}$ & CHED & \\
\hline Singapore & $\begin{array}{l}\text { Nat. Univ. of } \\
\text { Singapore }\end{array}$ & NUS & $\begin{array}{l}\text { BA (Arch) + } \\
\text { MArch }\end{array}$ & $4+1$ & $\mathrm{Y}$ & $\mathrm{Y}$ & & RIBA I, II \\
\hline Taiwan & $\begin{array}{l}\text { Nat. Cheng } \\
\text { Kung Univ. }\end{array}$ & NCKU & BArch & 5 & Y & $\mathrm{Y}$ & HEEACT & \\
\hline Thailand & $\begin{array}{l}\text { Chulalongkorn } \\
\text { Univ. }\end{array}$ & $\mathrm{CU}$ & BArch & 5 & $\mathrm{Y}$ & $\mathrm{Y}$ & ACT & \\
\hline
\end{tabular}

${ }^{1}$ QS ranking of Architecture Schools (top 25 in Asia, 2015). ${ }^{2}$ QS ranking of universities by countries/Asia (top 15 universities in each nation, 2015). ${ }^{3}$ XJLU is a joint venture of a Chinese and a British partner, and as such it has not yet an independent consolidated ranking. However, its Chinese partner is within China's top 15, and the British partner is among the UK top 25. ${ }^{4}$ RIBA Part II and NBAA professional accreditation in process. ${ }^{5}$ ITB adds a one-year MArch program into a four-year BA (Arch) program to complete a whole five-year cycle of architectural education, needed to receive KAAB Substantial Equivalence (KSE) recognition. Students holding a BArch degree from different schools need to enroll in a longer two-year version of the MArch program. ${ }^{6}$ International accreditation for three years, $2016-2019$ by KAAB. ${ }^{7}$ On the Kyoto homepage, there are several documents submitted to JABEE, but not yet an accreditation result. ${ }^{8}$ JUAA is a national higher education accreditation organization that certifies universities, not specific programs.

Table 2. List and abbreviations of accreditation institutions.

\begin{tabular}{cl}
\hline Abbreviation & \multicolumn{1}{c}{ Full Name } \\
\hline ACT & Architect Council of Thailand \\
ARB & Architects Registration Board of Hong Kong \\
CAA & Commonwealth Association of Architects \\
CHED & Commission of Higher Education (Philippines) \\
COA & Council of Architecture (India) \\
HEEACT & Higher Education Evaluation and Accreditation Council of Taiwan \\
HKIA & Hong Kong Institute of Architects \\
IAI & Indonesian Institute of Architects \\
JABEE & Japan Accreditation Board for Eng. Education \\
JPA & Public Service Department (Malaysia) \\
JUAA & Japan University Accreditation Association \\
KAAB & Korean Architectural Accreditation Board \\
LAM (or BAM) & Board of Architects Malaysia \\
NBAA & National Board of Architectural Accreditation (China) \\
PAM & Malaysian Institute of Architect \\
RIBA & Royal British Institute of Architects (UK) \\
RICS & Royal Institution of Chartered Surveyors (UK) \\
\hline
\end{tabular}


Table 3. List and abbreviations of degrees.

\begin{tabular}{cc}
\hline Abbreviation & Full Name \\
\hline BArch & Bachelor of Architecture \\
BA (Arch) & Bachelor of Arts in Architecture \\
BA (AS) & Bachelor of Arts in Architectural Studies \\
BEng & Bachelor of Engineering \\
BsArch & Bachelor of Science in Architecture \\
BSc & Bachelor of Science \\
BSSc (AS) & Bachelor of Social Sciences in Architectural Studies \\
MArch & Master of Architecture \\
MsARCH & Master of Science in Architecture \\
\hline
\end{tabular}

\subsubsection{Professionally Accredited Curricula}

To avoid confusion, we refer to "architect" as defined by the International Union of Architects (UIA) guidelines.

The designation "architect" is generally reserved by law or custom to a person who is professionally and academically qualified and generally registered/licensed/certified to practice architecture in the jurisdiction in which he or she practices and is responsible for advocating the fair and sustainable development, welfare, and the cultural expression of society's habitat in terms of space, forms, and historical context [30].

We study architectural education programs that grant an academic qualification for registration and practice of architecture as stated above. Usually each country has one or several organizations responsible of the accreditation of the academic architectural schools and their professional degrees [31-43]. Some organizations such as the Royal British Institute of Architects (RIBA), the Royal Institution of Chartered Surveyors (RICS), the Commonwealth Association of Architects (CAA), and recently the Korean Architectural Accreditation Board (KAAB), also provide international along with national accreditation [44-46]. These institutions set minimum curriculum requirements that each school develops in its own unique way. The present study does not intend to analyze these accreditation institutions or their standards. We refer to them only as we are studying architectural academic curricula that are professionally accredited. To better define the scope of the study, we included only professional programs specific for architectural registration from the first year of higher education. Therefore, to avoid excessive dispersion into programs that would be difficult to compare, we excluded all professional graduate or post graduate programs that train professionally students with previous grades from majors that are not specifically architectural. In summary, the present research refers solely to accredited professional programs, specifically architectural, from the first year undergraduate education, that grant whichever degree is required to apply for an architectural license, independent of the degree name (Bachelor or Master). Table 1 shows each of the selected schools sorted by country, with their basic degree and accreditation information. Table 2 lists the name and abbreviations of each accreditation institution, and Table 3 lists the full denomination and the abbreviations of all degrees listed in Table 1.

\subsection{Research Methods}

Once the schools are selected, their curricula are studied from two perspectives, qualitative (the specific sustainable issues addressed) and quantitative (the weight of sustainability related courses relative to the total required courses). To be completely objective, all information is obtained from each university's published media in their respective websites. Since the course titles are often misleading, we checked also their detailed contents in the published syllabi. 


\subsubsection{Qualitative Study}

All courses dealing with sustainability issues are identified, selected, and placed in a course matrix with their title and required credits, within the proper semester where they are taught. The education timeline is often neglected as we saw in the literature review, where only one of the cases reviewed took this into consideration [10]. However, the sequence in which course contents are taught along the program can show how consistent the curricula are, and therefore can uncover hidden individual strengths or weaknesses. For our purposes, we made an effort to consider sustainability in a comprehensive way. Although academic requirements in sustainability are often identified with energy efficiency and carbon emissions reduction, we tried to be inclusive of the widest range of sustainability issues addressed in the courses, using as a reference the three basic pillars of sustainability: Environment, Society, and Economy [47].

By scanning the respective curricula course names, their syllabi, and where possible the assigned student performance criteria (SPC) or expected student output, we picked all courses where sustainable issues are a substantial component of their respective contents. This selection had to be done case by case, and the authors had to check continually for consistency. For example, a course where one lesson out of 18 deals with a sustainable issue is excluded and considered a general major course. Another course in which one or several sustainable issues are an essential part of the main objectives, or represent a significant part of its contents, e.g., one-third or more, has been included in the study as a specialized course. A further distinction is made between required and optional courses. The required courses interest us most, as they are the common basic formation all graduates will receive. Optional courses are also important, however, as they provide a useful indication of the vision each school has for sustainability either as core knowledge, or as a more optional and specialized field. Exceptional academic systems, as those of Japanese schools, required a special approach for comparability in our study, but in order not to extend this section too much, they are explained in the discussion.

To provide better information on the nature of the courses, we classified them into three categories:

i General and conceptual theoretical courses, including cultural, historical and social issues. For a quick overview, in the course matrix we coded them in blue, and for optional courses in light blue with text in italics.

ii Technological courses, dealing with energy efficiency, architectural environment understanding, design and control, building systems and systems integration, efficient envelope design, life cycle analysis (LCA), environmental and health issues of construction materials, and any other course strongly related to sustainable technologies. In the course matrix we coded them in dark yellow, and for optional courses in light yellow with text in italics.

iii Design studio, architectural design courses with clearly integrated single or multiple sustainable issues. In the course matrix we coded them in dark green, and for optional courses in light green with text in italics.

\subsubsection{Quantitative Study}

Once the courses are identified, categorized and placed in the course matrix, a quantitative study was conducted to evaluate the relative weight of the sustainable courses within the curriculum. A rough discussion based only in the number of courses opens the section, followed by a more detailed study based on the academic credits assigned to each course, and the total number of credits required for achieving the professional degree in each institution. Since the definition of credit differs among schools, for comparison we used only relative values as percentages. The study compares the data in three ways:

i. Relative weight of sustainability related courses by category: required courses only

All schools are placed side-by-side in a bar graph, showing the total weight of the required courses included in each of the three sustainability categories by percentage (\%) of credits, using the same color coding as in the course matrix for required courses. 
ii. Relative weight of sustainability related courses by category: all required and elective courses

All schools are placed side-by-side in a bar graph, showing the weight of each of the three sustainability categories by percentage (\%) of credits, using the same color coding as in the course matrix for required courses, adding also the optional courses as a fourth category, all merged in a single bar in grey color. This gives us an approximate idea on the trends and orientations of each school, as well as their philosophy regarding the nature of sustainability education being basic or optional specialized knowledge.

iii. Required sustainability credits to total graduation credits ratio

All schools are placed side-by-side showing the weight of the required sustainability courses by percentage of credits related to the total required for graduation. Optional sustainability courses are removed from the table, in order to show how much sustainability education would be common to all graduates from the same school, even when a portion of the remaining required credits might (or might not) include additional, optional sustainable courses.

\subsubsection{Comparison and Analysis}

Using the course matrix and the quantitative graphs as a reference, all school curricula are compared and analyzed to identify coincidences, national or regional trends, individual uniqueness, and so on, and then the discussion leads to the findings and conclusions of the present study, and suggestions for further research steps.

\section{Discussion and Findings}

\subsection{Curricula Analysis by Countries}

For the qualitative analysis all data are condensed as a matrix graph in Figure 1, with the list of abbreviations for the courses in Table 4. Courses are color coded as explained in the Methodology. For more detail an expanded matrix table of schools, courses and credits is available for download in the Supplementary Materials Section (see Table S1), which is elaborated in the same way with further detail for full course names, credits and annotations. Table A1 in Appendix A contains a numerical summary of the courses credits. 


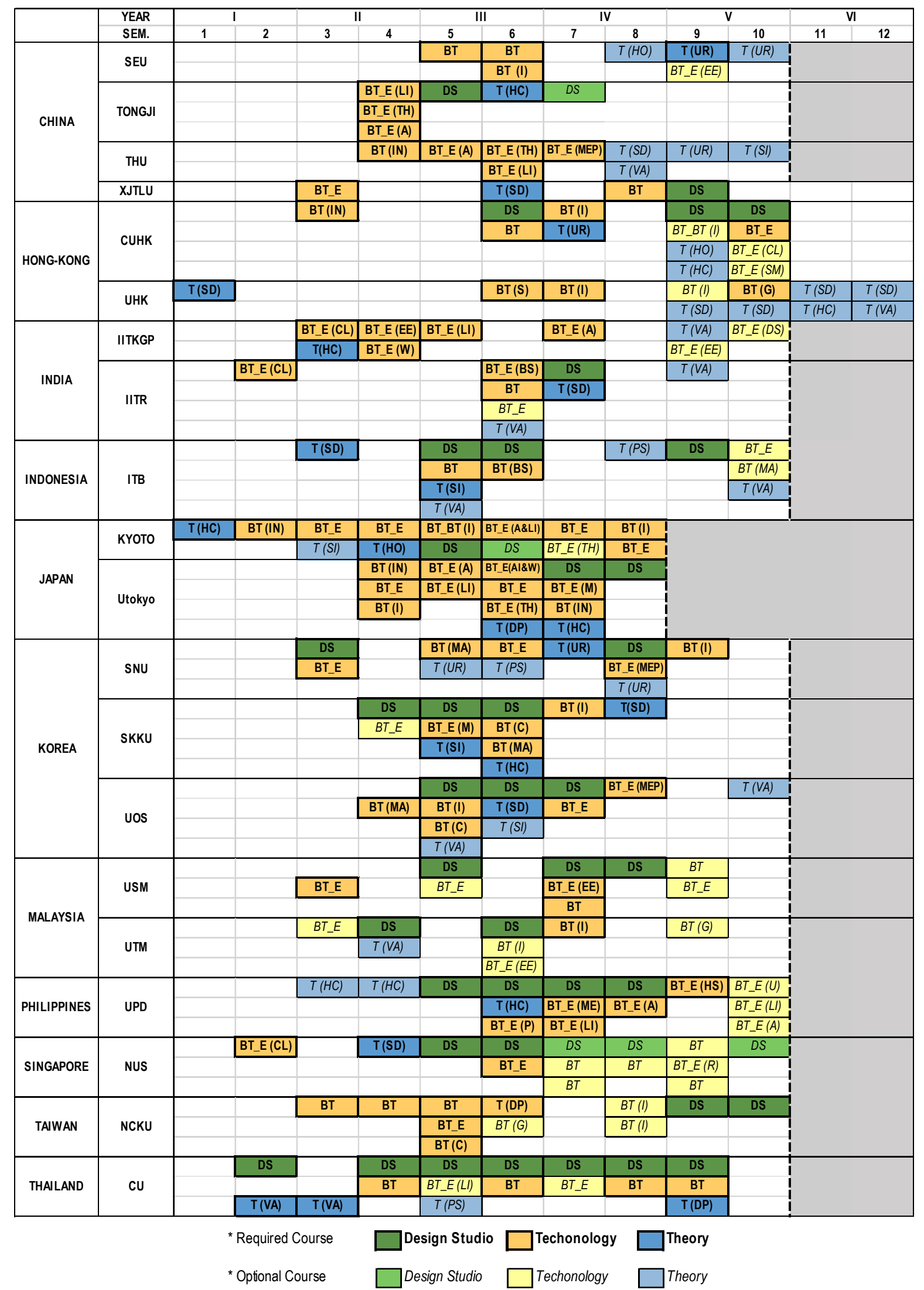

Figure 1. Schools and sustainable courses matrix graph in abbreviated version (for more detail see Table S1, available for download in Supplementary Materials section). 
Table 4. List of abbreviations used for courses names in Figure 1.

\begin{tabular}{|c|c|c|c|}
\hline Abbreviation & Full Name & Abbreviation & Full Name \\
\hline DS & Design Studio & BT_E (HS) & Health \& Safety in Building \\
\hline BT & $\begin{array}{l}\text { Building Technology, } \\
\text { Building Physics }\end{array}$ & BT_E (LI) & Lighting \\
\hline $\mathrm{BT}(\mathrm{C})$ & Construction & BT_E (M) & Mechanical \\
\hline $\mathrm{BT}(\mathrm{G})$ & Green Building & BT_E (MEP) & Mechanical, Electrical, Plumbing \\
\hline BT (I) & $\begin{array}{c}\text { Integration, Building System, } \\
\text { Façade }\end{array}$ & BT_E (P) & Plumbing \\
\hline BT (IN) & Introduction & BT_E (PO) & Pollution \\
\hline BT (MA) & Material & BT_E (R) & Renewable Energy \\
\hline $\mathrm{BT} \_\mathrm{E}(\mathrm{U})$ & $\begin{array}{l}\text { Utilities for Building } \\
\text { Interiors }\end{array}$ & BT_E (SM) & Simulation \\
\hline BT_E & Environmental (Engg. Tech.) & BT_E (TH) & Thermal \\
\hline BT_E (A \& LI) & Acoustic \& Lighting & BT_E $(\mathrm{W})$ & Water \\
\hline BT_E (A) & Acoustic & $\mathrm{T}(\mathrm{DP})$ & Design Planning, Programming \\
\hline BT_E (AI \& W) & Air \& Water & $\mathrm{T}(\mathrm{HC})$ & History, Culture, Theory \\
\hline BT_E (BS) & Building Services & $\mathrm{T}(\mathrm{HO})$ & Housing \\
\hline BT_E (CL) & Climate & $\mathrm{T}(\mathrm{PS})$ & Conservation, Preservation \\
\hline BT_E (DS) & Disaster Resistant & $\mathrm{T}(\mathrm{SD})$ & Sustainable (Design, Architecture) \\
\hline BT_E (EE) & Energy Efficient & $\mathrm{T}(\mathrm{SI})$ & Site (Landscape) \\
\hline
\end{tabular}

\subsubsection{China}

In China we selected three of the most influential and well established schools, all with five year professional BArch programs. Firstly, Southeast University (SEU) in Nanjing is not only the oldest School of Architecture in China and Asia, founded in 1902, but also the sole Chinese school with a Pritzker Prize winner among its alumni, Wang Shu [48]. Its curriculum is centered on design as its backbone, and stresses the quest for a comprehensive and practical education [49]. Even though QS does not include it among the six Chinese schools among Asia's top 25, the Chinese Ministry of Education consistently ranks it among the country's top three [50]. Tshinghua University (THU) in Beijing is consistently regarded as one of the top universities in China and the world [25]. Its School of Architecture, founded in 1946, stresses the importance of the Sciences of Human Settlements, especially in the rapidly growing Chinese context, in trying to balance education, research and practice [51]. The reputation of Tongji University (Tongji) in Shanghai is also internationally outstanding [25]. Its architectural program was first established in 1952, with a clear focus on modernity and innovation, while at the same time trying to blend modern technology with the regional culture. Integration and pluralism are among its philosophy keywords [52].

The fourth example we included is the very young $\mathrm{Xi}^{\prime}$ an Jiaotong Liverpool University (XJTLU) in Suzhou, just East of Shanghai, founded in 2006 as an international joint venture between two prestigious and well established universities, $\mathrm{Xi}^{\prime}$ an Jiaotong University and Liverpool University. It is the only of the four Chinese schools in the study that follows RIBA guidelines, with a sequence of four years BEng followed by two year MArch, now in the process of RIBA part II and NBAA accreditation [53]. It is also the only one that offers its complete professional curriculum entirely in English. (SEU has a Pre-professional Bachelor degree in English, but the full five-year professional program is taught in Chinese) [54]. Its School of Architecture is clearly design centered, with a focus on creativity and critical thinking. While aiming at a global modern architecture, it also emphasizes the rapidly changing socio-cultural reality of China and the specific urban context of Suzhou [55]. The curricula of these four schools are diverse, but it is possible to appreciate some connection between SEU and THU. Tongji is close to them in contents but different in course progression strategy. In contrast, XJTLU has very different educational approach.

Starting from this last one, in XJTLU only three specific courses deal with sustainable issues, all technology oriented, and spaced in three different years in the pre-professional undergraduate 
period: Introduction to Environmental Science (centered on energy and lighting) in the third semester, Environmental Design and Sustainability (elaborating on the previous course) in the sixth semester. Architectural Technology in the eighth semester has a more ambiguous statement regarding sustainability [53]. This scarcity in specialized courses may be compensated by the inclusion of several sustainable issues in other courses, as "Eco-cities" in the Urban Studies course (third year), or local urban and cultural awareness in most design studio courses. However, even when mentioned, these issues are not clearly developed as core contents of the courses, and are thus not included in the study [56]. The Master's program includes both urban regeneration and social-cultural studies among its five main concerns. Design Studio 1 (ninth semester) has a clear orientation on environmental, social and cultural issues [57].

The Tongji curriculum packs all three environmental technology courses into the fourth semester (lighting and thermal physics, and architectural acoustics), which are applied in the following semester's Design Studio. Social and Historical Analysis course in the sixth semester closes the required sustainable education, which expands along three consecutive semesters. One optional course worth mentioning is offered in the next semester, Interior Environment Design Studio $[58,59]$. Tongji is the only of the four Chinese schools in which a design studio course integrates clearly the previously learned environmental technologies.

SEU concentrates three technology based courses in the third year: Architectural Physics I in the fifth semester, and Architectural Physics II and Architectural Systems in the sixth semester. One last required course appears only one year later, Urban Environmental Survey, in the ninth semester. Remarkably, this is the only required course in the Chinese schools specialized in urban scale environmental studies. Their offerings of sustainable courses are complemented with three optional courses, distributed one by one in the final three semesters: Housing Design and Environmental Principles in the eight, Architectural Energy Conservation in ninth semester, and Urban Environment and Ecology in the tenth semester [60].

The THU offerings are slightly broader than at SEU, both in required and optional courses. However, their contents and sequence are very similar. Technology courses expand in progression along four semesters and with special intensity in the sixth semester. Introduction to Architectural Technology starts the process in the fourth semester, Architectural Acoustics follows in the fifth, Thermal Environment and Lighting Environment pack the sixth, and MEP Systems for Building ends the required courses cycle in the seventh semester. Optional courses expand into wider areas and concentrate in the last three semesters, just as at SEU. Ending the fourth year, there is a choice of Principles of Sustainable Design and Traditional Houses and Vernacular Architecture. Urban Ecology and Environmental Design appears in the ninth semester, and the last choice of Landscape Ecology in the tenth semester [61,62].

As a whole, all these Chinese schools place a clear emphasis on environmental technologies, which are taught concentrated or in close progression mostly in the second and third years. XJTLU is an exception, with courses being more dispersed. More varied issues are exclusively offered in optional courses as specialized studies in the fourth and fifth years. It is worth mentioning that the only sustainability integrated design we found is also optional.

\subsubsection{Hong Kong}

Hong Kong is a well-known global educational power, which in spite of its reduced size holds no less than four schools of architecture among Asia's top 25 [28]. We selected for the present study the architecture schools of the University of Hong Kong (HKU) and the Chinese University of Hong Kong (CUHK), the oldest universities in the city, consistently ranked among its top institutions [29]. Both schools follow a $4+2$ year system concluding with a professional master's degree accredited by HKIA, ARB and RIBA, to which HKU also adds NBAA and CAA. They provide a well-balanced undergraduate program, with a very specialized master's program. HKU tries to provide a comprehensive education based on the uniqueness of Hong Kong with its double nature as both a Chinese and a global city. Its Faculty of Architecture has its origin in 1950, and after several changes it reached its current organization in 2012 [63]. CUHK also stresses the special position 
of Hong Kong in the center of Asia's rapidly growing urbanization, providing a wide theoretical background in humanism, technology, and sustainability [64,65].

The HKU undergraduate curriculum centers on the design studio, supported by basic core theory courses, addressing sustainability in a general manner, with more intensity in environmental technology. It is one of the two exceptional cases in this study where sustainability teaching starts in the first semester, with the general course Sustainability and the Built Environment (the other being Kyoto University). Two years later, the remaining two basic technological courses appear: Building Technology III in the sixth semester, focused on sustainability, and Building Technology IV the following semester, dealing with integrated building systems in four perspectives: environment, construction, design and life cycle analysis (LCA). A variety of sustainable issues are scattered around other courses of an urban, cultural or technological nature, although none of them is really specialized. In the master's stage, one more required course completes the basic education in sustainability, Design and Technology of Sustainable Building, in the tenth semester. An extensive choice of optional courses can be taken along the two years. Five are technological: Sustainable Building Systems, Design Research in Architectural Sustainability, Sustainability Design Methods, Sustainability Field Workshop and Architecture by Nature; and the two others are more general theoretic studies: Design Research on Architecture and the Environment and Vernacular Architecture in Asia [63,66].

CUHK has course offerings very similar in contents and structure, although with differences worth mentioning. First, there is not any specific general course on sustainability. Second, the collection of required courses is larger in both undergraduate and graduate levels. Introduction to Building Technology starts the series in third semester. One year later, Building Technology III deals with environmental technology, taught alongside Design Studio $U 4$, which concentrates on passive environment design in the sixth semester, providing an interesting link between theory and design. The undergraduate program ends with Building Systems Integration, and a course on Land and City. The master's program has three required courses: Design Studios G1 and G2 (ninth and tenth semesters), plus one more technological course, Advanced Environmental Systems. Three optional courses reinforce the technological training: Facade and Technology, Climatic Spatial Planning and Performance Based Simulation in Design and Planning. Finally, two more optional courses widen the scope: China Urban Housing and Nature in Architecture, History and Design [65,67].

\subsubsection{India}

The two schools we selected in India belong to the prestigious India Institute of Technology (IIT) network. The IIT Roorkee (IITR) School of Architecture was founded in 1955, and IIT Kharagpur (IITKGP) in 1952. Although they are not among the oldest schools, their strong network with strong public support makes them especially relevant $[68,69]$. Both offer a five-year professional Bachelor degree accredited by the Council of Architects in India (COA) [34], and have a strong technological orientation, although their curricula are developed differently.

IITKGP has a clearer focus on a wider range of sustainability issues, including concepts of environmental, energy, climate responsive design and social and economic issues [70]. These are developed within six specialized basic courses on environmental technologies, most of them concentrated relatively early in the second year: Climatology and Solar Architecture, and Environmental Studies in the third semester, Energy Efficient Design and Water supply and Sanitation in the fourth. Two additional courses are more placed in the third and fourth years: Illumination and Electrical Services in the fifth semester, and Building Acoustics in the seventh semester. In the third and fourth years we find architectural design studios integrating sustainability issues. In the fifth year, all sustainable architecture related courses are electives. These include Traditional Architecture, Energy and Environmental Systems for Green Buildings, and Disaster Resistant Building and Management. This last course is based on environmental awareness and sustainability concepts, including disaster management technologies [70]. 
IITR deals primarily with undergraduate level with structural engineering and planning related subjects, but sustainable architecture is also treated. In the second semester, Climatology in Architecture starts a series of eight sustainability related courses. Two years later, between the sixth and seventh semesters the bulk of sustainable education takes place. Four are required: Building Services (which includes practical lessons) and Building Technology I in the earlier, and in the latter sustainable architecture Design Studio IV is taught concurrently with Sustainable Architecture, a general theory course. Two optional courses close the sixth semester, completing the basic environmental technology training in Acoustics and Lighting, and expanding to the field of Vernacular Architecture. A Vastushastra course is the final option in ninth semester, deepening the study of traditional Indian knowledge on building harmonization with the environment [71].

Both schools have a strong technological orientation, IITR being the only one that integrates them in a design studio course, in the context of a very intensive sustainable program concentrated in the central part of the curriculum. IITKGP is much more progressive over time, with a larger requirement for technology related courses along the four semesters. In contrast, design integration does not appear in the curriculum, and cultural issues are only optional.

\subsubsection{Indonesia}

The Institute of Technology Bandung (ITB) claims to be the first School of Architecture in Indonesia [72] (p. 152). ITB as a whole is considered among the two top universities in Indonesia, with an outstanding global ranking in Art and Design [29]. Established in 1950, its last reorganization took place in 2005. Since 1983 its curriculum follows a $4+2$ BA(Arch) + MArch system. Although the two-year MArch program is still offered for students coming from other institutions, ITB students can follow a rapid $4+1$ in line with the more general five-year system in the region [73]. In 2013, the School of Architecture ITB received an official notification from the Korean Architectural Accrediting Board (KAAB) [38], stating that a full five years KSE (KAAB Substantial Equivalence) recognition was granted for the professional degree [74]. The required classes are balanced in design, theory, and technology. The theoretical courses are Sustainable Built Environment in the second year and Site Planning and Design Studio in the third year. In the technical field there are two required and one elective courses: Building Physics and Building Services in the third year and Analysis of Built Environment in the fifth year. These lectures are integrated with some studios, although not intensively: Architectural Design Studio III and IV in the third year, and Design Studio 1 in the fifth year. Most interestingly, the multiple electives emphasize an understanding of the region: Appropriate Architecture in the third year (dealing with design with consideration of a site, its climate, and the cultural and social context), Preservation of Historic Building and Sites in the fourth year, Bamboo Building Technology and Vernacular Architecture of Indonesia in the fifth year [74].

\subsubsection{Japan}

We selected the two top Japanese universities [28], Tokyo and Kyoto, both well-known global educational leaders [29]. The University of Tokyo (U-Tokyo) Department of Architecture, founded in 1877, is the oldest and most respected in Japan [75], the only Asian school with three Pritzker awarded alumni [48]. Kyoto University (Kyoto) follows also with a long history starting in 1920 [76]. Both schools are situated within an engineering context with a rich technological orientation, differing from the more common design centered schools. Japanese schools have several unique features worth mentioning. Their BArch is a four year program, the shortest among all studied here [77,78]. There is not a specific professional architectural accreditation, but a general engineering accreditation system carried by the Japan Accreditation Board for Engineering Education (JABEE), established in 1999 [36]. There is also the Japan University Accreditation Association (JUAA), established in 1947, that certifies universities as a whole, not individual programs [37]. In Japan there is not an exact equivalent to the Occidental architect's license. Nonetheless, the profession sticks to the traditional kenchikushi (literally translated as "construction professional"), a professional registration category inclusive of 
"building engineers who engage not only in the fields of architectural design and supervision, but also construction, administration, education and other related fields" [79]. Therefore, the BArch is not a strict requirement for an architectural license, as the system is flexible enough to allow different alternatives in applying for the kenchikushi examination, and the JABEE or JUAA accreditation requirement is not explicitly mentioned [79]. Under these unique circumstances, it is possible to understand why U-Tokyo has only JUAA official certification [37], while Kyoto is only now in the process of JABEE accreditation [80]. A last unique feature is their credit systems. Both schools have a very small percentage of fixed required courses, with the bulk of basic education consisting of a selection of a minimum number of what they call "required optional" (gentei sentaku kamoku), to distinguish them from the also existing conventional optional courses (hyoujun sentaku kamoku) [81,82]. For this reason, in this study we made a rough estimation of the sustainability related courses based on the percentage of the "required optional" (for example, U-Tokyo requires 58 "required optional" credits out of 68.5 , resulting in a percentage of approximately $80 \%$ ) [81].

U-Tokyo defines its philosophy as a blend of engineering and design, seeking both specialist and generalist professionals, and stressing the importance of the origins of architecture as a discipline and Japanese culture [83]. Its architectural training is heavily packed with technological courses concentrated in two years (from the fourth to seventh semesters). The fourth semester offers Introduction to System Design in Buildings, Principles of Environmental Engineering, and Exercises of Architecture and Building Systems (environmental). The following semester's two courses deal with Acoustic Environment of Building and Lighting and Visual Environment of Building. The sixth semester continues with Thermal and Air/Water Environment of Building, with an Environmental Systems Design course and Principles of Architecture Design III, focusing on environmental and behavioral issues. The senior year starts equally packed with Design Basics III, focused on environmental, historical and urban integration issues, History of Japanese Dwelling, and two final technological courses, Mechanical Equipment in Building and Introduction to Advanced Environmental Planning and Engineering. The last semester offers Design Basics IV, with special stress on environmental and technological integration in design. This short and extremely intensive educational approach of U-Tokyo is very unique. The positive side is how the theoretical and practical courses are balanced and alternated, so theoretical understanding, application, exercising and design implementation go together. One issue is the emphasis on the technological approach to environmental issues, with the urban and social issues being more marginal. Another concern is the rhythm demanded of students. However, the short time helps keep the courses fresh, preventing the usual "forget after the exam", as they are continually exercising and extending in the following courses. Altogether, integration and connection between fields seems easier and more natural than in longer and more divided programs.

Kyoto states as its philosophy a quest for an interdisciplinary knowledge in natural, cultural and social sciences, always with a focus on its technological character [76]. It offers an equally intense and varied sustainable education program, but with interesting differences from U-Tokyo, its plan being more spread along the four-year curriculum, and the courses are wider in scope. Sustainable education starts immediate in the first semester, with the general course Environment and Ecology. The following semester starts the technology series with Introduction to Structural and Environmental Engineering. This series continues without stop at a rate of one course per semester: Environmental Engineering I and II, Building Environmental Systems, Architecture Lighting and Acoustics, Urban Environmental Engineering, arriving to the eight semester with two final courses: Building Systems Design Theory and Environmental Design Practice. Housing Planning focuses on integrated environmental, social and accessible design in the fourth semester, and Design Studio III in the following semester focuses on systems integration in design. Three optional courses complete the sustainable curriculum: Theory of Landscape Design in the third semester, Design Studio IV in the sixth semester focused on environmental and safety integration, and Architectural Thermal Environmental Design in the seventh semester [78,82].

As a whole, these two schools show that it is possible to create a complete and balanced program even in a short four-year period, and furthermore, that it is still possible to have very different 
approaches, all with apparently good results, if we take the average quality of Japanese Architecture as a reference. There is, however, a long debate over the convenience of expanding the Japanese system to the now more universal five-year system [84].

\subsubsection{Korea}

In Korea we have selected three influential and well established schools, all of which have five-year professional BArch programs: Seoul National University (SNU) and the University of Seoul (UOS), both in Seoul, and Sungkyunkwan University (SKKU) in Suwon. SNU is one of the top universities in Korea and also a leading global university [25], with the nation's first and most reputed school of architecture established in 1946 [29]. SNU started its newest BArch curriculum in 2002 and pioneered receiving KAAB accreditation in 2007. Its curriculum pursues a total, integrated approach that includes architectural structure, technology, art, and culture in the architectural realm [85]. SKKU's international reputation is also outstanding [25]. Its Department of Architecture was founded in 1970 and updated its current BArch curriculum in 2003, aiming towards harmonizing sustainability and innovation, with emphasis on what they consider key fields in the near future: Media Technology, Sustainability and Global Experience [86]. UOS is a public institution sponsored by the Seoul Metropolitan Government. Its Department of Architecture was founded in 1975, and is also the first Korean school among three schools accredited in 2007 by KAAB. UOS aims at innovating and actively improving students' excellence in design and technical skills, with an emphasis on consciousness and training in environmental, social and economic fields. It also notes its fluid connection with other urban sciences departments, such as engineering, urban science and landscape [87,88]. Given their public character, both UOS and SNU emphasize ethical awareness and social responsibility.

For the respective curricula details, SNU offers two tracks: BArch (five years) and BSc in Architectural Engineering (four years). From 2016, SNU recruits students into an integrated program that share an enriched and collaborative common curriculum. After two common years, the students choose either BArch or BSc [89]. This common start pursues a total, integrated approach that includes architectural technology, design, and culture. Up to the second year, design studio and technology courses share subjects such as communication, structure, environment, and fabrication design. For sustainability, in the fourth semester, Architectural Environment System and Design Studio 3 (Architecture and Environment) provide a general introduction to the field [90]. From the third year of the BArch, technology courses appear in yearly sequence: Building Material and Architectural Environmental Planning (third year), Mechanical and Electric Systems for Building (fourth year) and Building Systems (fifth year). In the field of design, Architectural Design Studio 4-2 focuses on renovation in Asian cities. Architecture and Urban Design is taught in the same semester. Three elective courses related to urban sustainability appear from the third year: Asian Architecture and Urbanism, City Cultures and Urban Conservation and Architecture, City and Planning. SNU deals with sustainability through multiple courses that address specific issues in part of their syllabi, instead of concentrating the subject in a specific course [90].

SKKU has three design studios dealing with sustainability issues. Design Studio 2 is an exercise in small-scale renovation. Design Studio 3 is an intensive green studio, exploring building envelope design along with active and passive systems applied to high-rise buildings. Design Studio 4 deepens in building renovation at a larger scale. Four technology courses are provided in the third and fourth years: Building Mechanical and Engineering Service, Architectural Construction Management, Architecture Materials, Process $\mathcal{E}$ Structures, and Integrated Architecture Systems, in a manner that is very typical among Korean schools. There are three theory courses: Socio-cultural Context and Architecture (dealing with socio-cultural issues and ways of harmonizing Confucian features of architecture and the world with the modern society), Site Planning in the third year, and Sustainable Architecture (with an overview of ecological principles in architecture) in the fourth year. SKKU's curriculum concentrates its sustainable courses in the third year, rather than distributing them along different years [91,92]. 
UOS requires four technology based courses extending from the second to fourth year: Architectural Materials, Introduction to Construction Technology, Building Systems, Environmental Technology, and Mechanical, Electrical and Plumbing Systems. Theory is extensively taught in Sustainable Architecture as a dedicated course in the third year. Its syllabus is comprised of a complete overview of theories, tools and strategies, and their application to a wide range of issues: climate, materials, health, environment, energy and design assessment tools. Three elective courses are offered between the third and fifth year: Theory of Housing and Settlement (housing adjustment to their environment), Site Planning, and Architecture and Hanok (the Korean traditional wooden house considered an example of ecological and sustainable architecture). Design Studio 3 deals with building integration in continually changing urban settings. Design Studio 4 covers renovation or expansion of small buildings, addressing technology associated with the reuse of existing buildings. Design Studio 5 stresses design implementation of the previously learned sustainability theory, especially for site and natural flows, material use and energy, and passive strategies and environment control $[87,93]$. The approach of UOS Architecture, with the bulk of its sustainability education concentrated in the third and fourth years, achieves a well-integrated balance between conceptual and operative training. As a pioneering school in sustainability, its pattern has been followed by many other Korean schools, with the advantage of introducing complex subjects in the latter years, when the students have developed enough skills and understanding. This strategy also may turn into a disadvantage, as the students wait a long time to receive this education and may create a "design only" mentality, where the sustainability they learn in the latter years becomes just another technical course, instead of an essential part of their education and practice. Another issue we find is that the social sustainability is apparently not as stressed as the other aspects of sustainability.

In general, the architecture schools we studied in Korea have similarities in their curricula. Since many of them are in the context of College of Engineering, they have many dedicated technological courses, form basic theories to calculations and simulations leading to their practical integration in design. However, in general we could not find a consistent integration of theory into design, with theory and design courses being apparently isolated.

\subsubsection{Malaysia}

Malaysia has been working on becoming a regional educational hub, to be able to compete against well-established Singapore and Taiwan [24]. In the field of architectural education, it is outstanding, and counts with three schools among Asia's top 25, which belong to universities among the country's best four [28]. We include here two of them, Universiti Sains Malaya (USM) in Penang, and Universiti Teknologi Malaysia (UTM) in Johor. Both offer professional degrees in a system $3+2$ years, with professional accreditation from the Board of Architects of Malaysia (LAM); UTM also has accreditation from PAM and JPA, while USM adds RICS to its list [39-41,45].

The USM School of Housing, Building and Planning (SHPB) is comparatively modern, established in 1972. From its philosophy statement it is worth noting the concern for responding to global era challenges, and to achieve eco- and environmental friendliness. Basic sustainability training takes place in the first cycle, with one course on Environmental Science in third semester, dealing with natural environment and sustainability [94]. Architectural Studio 3, one year later, concentrates on sustainable and ecological approaches to design, with an emphasis on integration. In the same semester Environmental Science 2 is optional, and focuses on passive and active strategies and integration in design. The second cycle is more intensive. In the fifth semester, Architecture Studio 5 deals with social, cultural and sustainable approaches to neighborhood making, and Energy Efficient Design Technology elaborates on the previous courses. The following semester, Architecture Studio 6 exercises the integration of technology and design, applying also passive and active systems for energy efficiency. Finally, Building Technologies studies all environmental and sanitation technologies offered in the ninth semester. One optional course on Building Services Technology and one more on Energy Efficient Building Design Technology, both in the seventh semester complete the offerings $[95,96]$. 
UTM philosophy has a strong statement regarding cultural heritage and religion, with an emphasis on a balance of academic knowledge and practical skill, and a consciousness of internationalization and globalization. The UTM Faculty of Built Environment has its origin in 1974. Its sustainability education is simpler than at USM, and in the first cycle is organized around Design 4 and Design 6 in the third and fifth semesters. Design 4 is focused on the complexity of environmental issues. Design 6 as the first cycle capstone design aims for comprehensiveness, integrating social and environmental issues, together with more general architectural issues. Three optional courses in Environmental Science and Sustainability (third semester, of an introductory character), Building Integration and Performance and Energy Conscious Design complete the choices of the first cycle. The second cycle includes only one basic course, Advanced Architecture Technology and Integrated Design in the seventh semester, and one optional Green Building Design course [97,98].

Altogether, both schools share in common a studio centered approach, with some basic technology support at the undergraduate level. Both schools have a rather scattered process in that period, although USM has a stronger and more consistent offerings at the master's level.

\subsubsection{Philippines}

The University of the Philippines Diliman in Quezon City (Metro Manila) is consistently ranked as the top institution in its country [29]. Its Department of Architecture also claims to be the first in the Philippines. Founded in 1956, it offers a five-year BsArch professional program, from its origin, including high technical requirements [99]. It is worth noting that the Philippine accreditation system is extremely detailed, specifying guidelines not only for students' competencies, but also for courses, teaching hours and complete curricula with the distribution of the courses and their assigned credits [42]. Notwithstanding the relative freedom to develop the generic programs in different ways, much consistency among different school curricula is expected. The program at UPD is well balanced regarding sustainability, with ten required courses and five more optional ones, as a whole well distributed over the last four years, with a particular emphasis between the sixth and eight semesters [100]. The basic sustainability courses start with a long series of four consecutive design studios (Design $V$ to $V I I I)$ in third and fourth years. The first of these concentrates on context and site related issues, the following studies the application of architectural environmental technologies, and the latter two studios focus on integrated design. Parallel theory and technology courses support the design studios: Tropical Architecture and Utilities I in the sixth semester, Utilities II and III the following and Utilities $I V$ completing the series, altogether providing a very complete training on the basic environmental technologies. The optional courses are placed at both extremes, two courses dealing with the local and regional architecture, and three more courses in the tenth semester developing further in environmental technologies (interior, lighting, acoustics) [101]. As a whole, UPD is coherent with its original claim of technological excellence in education, and has a well-organized sequence of design studios with immediate support of parallel theory and technology courses; also worth noting is the concern for the local climate and building culture. If the additional culture and society oriented courses were basic and not optional, the whole curriculum would be better balanced.

\subsubsection{Singapore}

The National University of Singapore (NUS) is the country's oldest higher learning institute, considered and ranked as its top university, also with an outstanding global reputation [25]. Its architectural program was founded in 1958 [102]. NUS program starts with a pre-professional BA (Arch) degree. It consists of a general program accompanied by four tracks for specialization, one of which is Design Technology \& Sustainability (DTS). The MArch program adds one year to complete the professional degree, which is RIBA Part II accredited [103]. Students pursuing a professional degree program must decide in their junior year between either remaining in the mainstream design track, or opting for the specialized DTS track. Mandatory sustainability courses are developed along four semesters, starting in the second, with special emphasis in the third year. Sustainability learning 
starts with Climate Responsive Architecture, a course on the principles of passive building with holistic approaches to design solutions. In the fourth semester, Strategies for Sustainable Architecture focuses on built environment sustainability issues, including technological and environmental as well as social, cultural, and historic issues. In the sixth semester, Environmental Systems and Construction introduce fundamental building physics (thermal, lighting, acoustics), building materials, and systems from the perspective of environmental efficiency and sustainability, with an emphasis on integration [104]. Two design studios also in the third year integrate with design both the sustainability principles and the technologies learnt in the other courses. Design 5 projects demand a holistic awareness of the issues related to the environment, climate, context, technology, and building regulations [105]. Design 6 involves the integration of technology with the natural environment and urban context, with an emphasis on urban, environmental, and technological issues [106]. This completes the basic common required education, and anything beyond this belongs to the DTS specialized track starting the fourth year. This track elaborates on the integration of more advanced theory courses and complex design problems. Architectural \& Technology Design 1 studio (seventh semester) leads to detailing and technological development and resolution of architectural schemes. Next, Architectural $\mathcal{E}$ Technology Design 2 studio implements digital simulation tools for building performance design decision taking [106]. Specific studies on renewable energy and architecture are also unique to the DTS track [107].

In summary, this university's general approach shows well balanced theory and practice, emphasizing technological integration in design. Sustainability is dealt with widely and in detail. The techniques studied suit the peculiarity of Singapore's climate, where an understanding of nature and passive strategies are keys to reduce energy dependency [108]. NUS's strategy of creating a specialized DTS track is quite unique, creating highly skilled professionals. However, this division can also be a concern, preventing general architecture students from accessing deeper sustainability knowledge.

\subsubsection{Taiwan}

Taiwan is a rising educational power with growing relevance in the academic world [109]. Among its best schools, National Cheng Kung University's (NCKU) Department of Architecture in Tainan is ranked among Asia's top 25 [28]. Founded in 1944, it is also among the country's oldest. The pedagogical philosophy states that it first concerns the living environment, followed by technical skills. Humanistic, social, and environmental responsibilities are the keywords, after which technology appears [110]. It offers a five years accredited professional BArch degree [43]. The sustainability curriculum, however, seems heavily weighted toward technology, starting in the second year with one course on Architectural Environmental technology each semester. A very busy third year follows; its first semester is packed with three courses: the last of the Architectural Environment series, Environmental Control Systems, and a general course on Building Construction, which includes sustainability issues such as LCA (life cycle assessment) or efficient envelope design among its contents. This series ends in the sixth semester, applying the learnt theory in an Architectural Planning course that focuses on environmental and technological integration. After a one-year gap, the fifth-year Design Studio (studios 8 and 9) has a clear stress on environmental issues. Three optional courses complete the collection: Planning of Green Buildings in the sixth semester, and in the following Architectural Design Integration and Building Systems Design [111,112]. As a whole, the curriculum has a logical implementation, with a sequence of heavy technological training, one practical course and a final integration in the capstone design after a full year gap. Specialized options are in second half of the program. Humanistic courses do exist, but we could not clearly identify any of them with cultural or social sustainability.

\subsubsection{Thailand}

Chulalongkorn University (CU) in Bangkok is the oldest in Thailand, founded in 1917, with its Department of Architecture established in 1930. It offers a five-year BArch since 1945, and also an international program since 2007 [113]. CU is world class [25], ranks along Asia's top universities, 
and is recognized as the best institution in Thailand [29], also for its Architecture program [28], which is accredited by the Architect Council of Thailand [114]. Its philosophy calls for comprehensiveness and pays attention to the "environmental, cultural, economic and social interrelationships that generate the built environment", with special emphasis on the preservation of Thailand's tradition and on community engagement [115]. The sustainability curriculum is well structured, spreading progressively along the five years of education. For design studios, all eight Architectural Design courses ( $A D .1$ to $A D .8$ ), stress the significance of architecture's environmental impacts in various contexts. $A D .1$ introduces contextual site planning and $A D .2$ concentrates on ecological design, including intelligent and economical usage of materials and resources, and energy efficiency by designing in concert with the environmental circumstances. $A D .3$ and $A D .4$ deal with the specific conditions of the region's tropical climate. $A D .5$ focuses on an understanding of climate responsive design development. $A D .6$ again is oriented towards environmental responsiveness, and $A D .7$ addresses the integration of design and site and the environmental context, and the intelligent integration of climate-responsive elements in the design. Lastly, $A D .8$ includes research on the potential environmental impact due to the construction activity. A series of Building Technology and Construction modules (BTC.1-4), teach more complex environmental technologies in growing building scales. BTC.1 deals with environmental technology and passive systems for small-scale buildings. BTC.2 studies environmental control and building envelope systems for medium scale buildings and BTC.3 does the same for large scale and high rise buildings. BTC.4 specializes in high rise and high performance buildings. Interestingly, CU offers two courses about local conditions in the early years: Thai Architectural Heritage in first year, and Introduction to Thai Architecture in second year. Within the theoretical courses, Architectural Design Seminar in the fifth year is concerned with the environmental impact of large scale projects in their usage stage. A range of interesting electives in sustainability complete CU's sustainable curriculum: Introduction to Urban and Architectural Conservation, Daylighting in Architectural Design, both in the third year, and Pollution Problems and Control in the fourth year. CU deals with sustainability issues throughout the whole curriculum, which is quite ideal $[113,115]$.

\subsection{Comparative Analysis: Qualitative}

The discussion in Section 3.1 above, and its visual matrix summary in Figure 1 (along with the expanded matrix in Table S1, available for download in Supplementary Materials) reveal interesting findings when we compare all curricula across countries and schools, as we will do in the following paragraphs.

\subsubsection{Course Density Areas}

One first fact is the concentration of sustainability courses in the central part of the curricula, with a peak between the fifth and seventh semesters, the majority of them encased in a slightly wider period, between the fourth and ninth semesters. Only Hong Kong (HKU) and Japan (Kyoto) require an introductory course in the very first semester, and out of the 20 schools studied, only five have a sustainability course in the first year-IITR, NUS and CU, apart from the two above mentioned. Considering sustainability is an inherent part of architecture, as many schools claim in their philosophy, it is quite surprising among the top institutions that sustainability education appears relatively late, as something added and not consubstantial to architecture. This concern is more pronounced in some schools, delaying them until the fourth and even fifth semesters.

\subsubsection{Curricula Length and Intensity}

Another fact is the general trend of implementing professional programs within a five-year time frame, NUS and XJTLU being the exceptions with a longer six-year requirement. In contrast, this is shorter in Japan, with only four. By comparing all programs related to their length, another interesting finding becomes apparent: program length and intensity of sustainability education are not necessarily related. Japanese schools offer on average a total of 14 sustainability related courses. 
The much longer NUS program only matches this in the specialized DST track, its general program containing five courses. At XJTLU there are only four. All these numbers include the total of basic and optional courses.

\subsubsection{Curricula Courses Sequence Categories}

Going into more detail, it is possible to find different methods or strategies regarding the organization of the courses sequence or distribution along the curricula: (a) continuous curricula; (b) short intensive curricula and (c) scattered curricula, with some cases sitting ambiguously in between two or even three of these methods.

The first and most remarkable is the continuous curriculum, stretching without or almost without stop semester after semester. There is a long version of this trend, lasting about three years or more, and a shorter version, where this process expands for about two years. The schools following this strategy are scattered around different nations, Japan, China, Thailand, Korea and to some extent Singapore, without having data enough to identify clear national preferences. Kyoto is the leader in the long version, being the only school with sustainability courses in every semester, from first to eight. $\mathrm{CU}$ follows closely, although only if we consider the optional courses, otherwise it would fall under the shorter version. In the short version we have also THU, and SNU, except for a small gap. NUS can be also considered here, but only for the specialized DST track, the general architecture track being much shorter and partly scattered.

In the second method, short intensive curriculum, a large number of specialized courses are packed in a few semesters. The most extreme case is U-Tokyo, with 13 courses taught between the fourth and seventh semesters, with a special emphasis in the latter two (although this school also could qualify as continuous curriculum, the second feature is more prominent). Other schools are not so radical and are mixed with other categories.

The third strategy is the scattered curriculum, in which individual courses or small course packages are isolated in their respective semesters. The largest number of schools fit in this category: SEU, XJTLU, HKU, IITKGP, USM, UTM. By country, these include notably Hong Kong, Malaysia, two among the Chinese and one of the Indian schools. Sometimes the distinction between methods is not clear, and therefore the remaining six schools are in between these examples. The most common intermediate cases are those with a mix of continuous and intensive categories: UPD, and two of the Korean schools, SKKU and UOS. The mix of concentrated and scattered is evident in the Indonesian ITB, the other Indian IITR, and CUHK when we take into account all the options in the fifth year. Finally Taiwan's NCKU shares characteristics of all three methods.

\subsubsection{Design Studio as the Real Backbone for Sustainability Education}

The matrix in Figure 1 also shows the degree of strength of design studios not only in the number of modules dedicated to the application of sustainable issues, but in how they articulate the whole sequence of theory, technology and design throughout the curriculum. Thailand's CU is the most remarkable example of a well-organized sequence of seven design studios along with other related courses in the program's five years; NUS and UPD follow with five and four studios, respectively. With three studios and still in this category are Hong Kong's CHUK, Indonesia's ITB Korea's SKKU and UOS and Malaysia's USM. On the other side of the spectrum, without any specialized design studio, are China's SEU and THU, Hong Kong's HKU and India's IITKGP. The remaining schools do have at least one or two studios.

\subsubsection{Balance between Technology, Theory and Design}

With a general view to the courses in Figure 1, technology related courses are by far the most numerous. Out of the approximately 100 courses in the matrix, more than half relate to technology, with environmental science, technology and systems being the most common subjects. Theory courses fall to 51, and Design to 45 . There are schools with a clear technological strength, as both schools in Japan, 
SEU, Tongji and THU in China, ITKGP in India, or NCKU in Taiwan. Many schools, however, show a good balance among the three areas: CHUK in Hong Kong, IITR in India, ITB in Indonesia, Kyoto in Japan, all three Korean schools (SNU, SKKU and UOS), UPD in Philippines and CU in Thailand.

\subsubsection{Global and Local Features}

Regarding the content, many of the modules studied are similar to those of most schools in the world, especially those in the technology fields. Local features may be apparent in how these courses are implemented; e.g., by stressing an understanding and application of passive strategies in tropical climates, especially in developing countries, but not exclusively, as we saw in Section 3.1; or by providing special modules as IITKGP school does, teaching technologies to deal with the natural disasters frequent there, or dealing with basic water infrastructure and sanitation. Theoretical general courses also more often introduce local features, especially the study of ancestral or historical typologies suitable to local climates, materials and societies that can inspire sustainable contemporary solutions. Korean traditional house or Hanok, Malay traditional and colonial houses (USM), Chinese traditional architecture, and Philippine bamboo architecture (UPD) are good examples of this. More interesting is the appearance of local philosophies in some modules, sometimes influenced by religion. India's ancestral Vatusatra is an elective specialized course at IITR. In a technological Korea, SKKU takes Confucian philosophy as one of the main principles of the school, considering it a permanent reference to achieve harmony in society and harmony with nature, although there is not any specific course dedicated to this subject.

\subsection{Comparative Analysis: Quantitative}

\subsubsection{Course Numbers}

A first approximation of the quantitative analysis is the total number of sustainability related courses, for which the matrix in Figure 1 is a good reference. The average of the 20 schools in the study is about 10, including basic and optional courses. The largest number can be found in Thailand's CU, with 17 courses, closely followed by Philippines' 15 and Japan's 14. The lowest number is in China, with an average of 6.5 courses, Malaysia with 6.5 and India with 7.5. Singapore is on both extremes if we refer to the general architecture design track; only 5 courses are provided, but if we refer to the specialized DST the number raises to 14 .

\subsubsection{Course Credits Relative Weight}

The above discussion of the number of courses provides interesting information, but for a more accurate analysis we need to refer to the credits, as course credit weight differs depending on their nature and on the different schools and national criteria. For this reason the number of credits has been studied in relative percentages, so data of different schools can be compared. For the unique cases of U-Tokyo and Kyoto's credit counts, please refer to the comments in Subsection 3.1.5 above, Table A1 notes 1 and 2 (in Appendix), and Table S1 notes 5 and 6 (available for download in the Supplementary Materials Section). The number of credits in each module used for calculations is displayed in the aforementioned Table S1. Table A1 in Appendix summarizes all courses credit totals by universities and categories, which are the values used in the elaboration of the graphs in this section.

Figure 2 displays the relative weight of the different categories of required sustainability related courses in each school.

In this graph, design courses bear more weight compared with the rough course count in Subsection 3.3.1. Both Malaysian schools are clearly design centered, this category filling between $70 \%$ and $80 \%$ of the sustainable curriculum, the remaining being dedicated entirely to technology. NCKU is an intermediate case, in which technology and design are near 50/50 in proportion. In the other extreme of the spectrum we have THU in China, with $100 \%$ of the required curricula exclusively technology based. SEU also in China, HKU in Hong Kong and IITKGP in India also exclude design 
from their sustainable curricula, technology being between $70 \%$ and $80 \%$ of the total, and the remaining consisting of general theory courses. All other schools offer the three categories, the examples of Tongji and XJTLU in China being the most balanced. Design is around half the total, followed by technology and a smaller proportion of general theory Singapore's NUS, Thailand's CU, Philippines' UPD, Korea's UOS and SKKU, and Hong Kong's CHUK. ITB in Indonesia increases Design to over $60 \%$, with technology and theory nearly in equal percentages. The remaining schools progressively de-emphasize design in favor of technology: SNU in Korea, Tongji in China and IITR in India, all with design around $30 \%$ and theory between $10 \%$ and $20 \%$; U-Tokyo has $20 \%$ and Kyoto only $10 \%$ in design contents, with technology occupying near $70 \%$ in both cases.

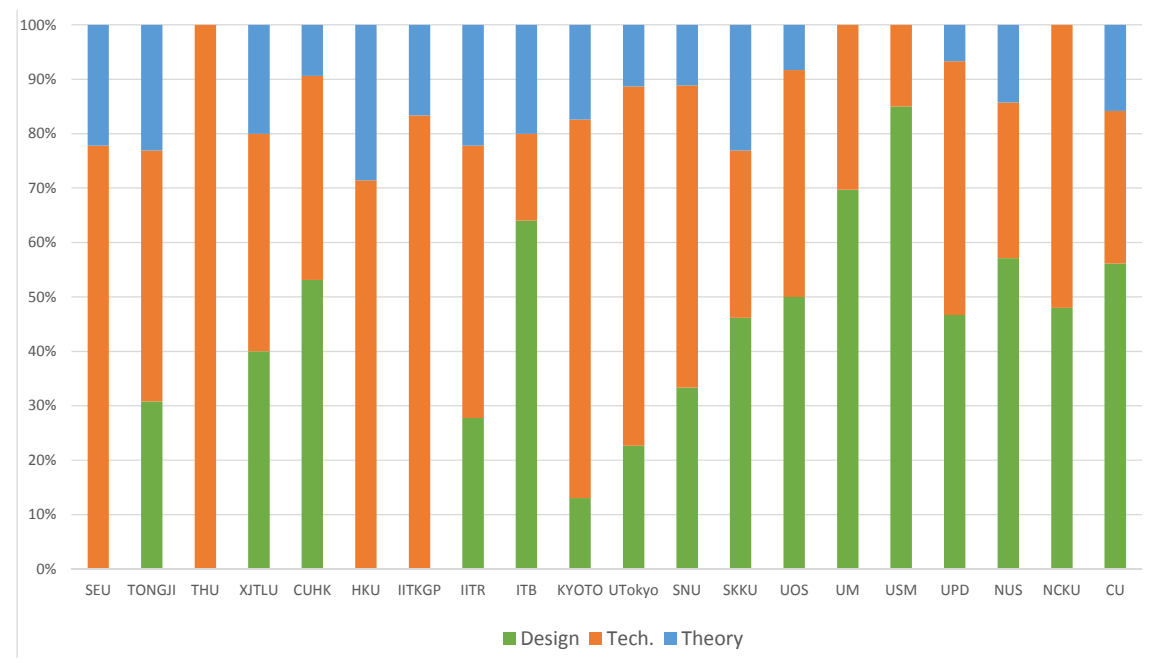

Figure 2. Relative weight of sustainability related courses by category: required courses only.

Figure 3 shows the same calculation, but adding all optional sustainability related courses as a fourth category. We did not distinguish categories among the optional courses, as our interest was to see how much of the offerings is considered a basic requirement, and how much is considered only specialized knowledge.

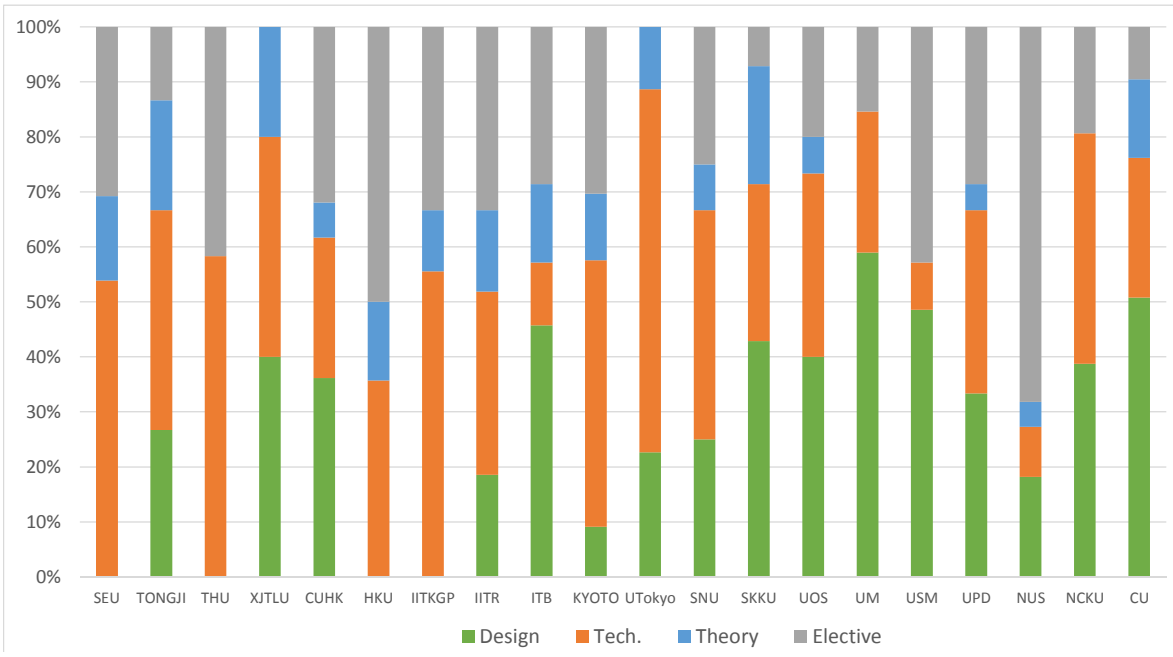

Figure 3. Relative weight of sustainability related courses by category: All required and electives courses. 
Two schools define as basic all their sustainability courses, XJTLU and U-Tokyo. SKKU, CU and Tongji follow, with optional courses being around only $10 \%$ of the total. On the opposite end, NUS is the most radical, as $70 \%$ of its sustainability program is specialized. HKU offers near $50 \%$ of optional courses, while THU and USM reduce them to around $40 \%$. All remaining schools are intermediate cases.

Finally, Figure 4 shows the proportion of required sustainable credits, related to the total required for graduation, and provides good information on how important these specialized sustainability courses are when compared with the whole of the curriculum.

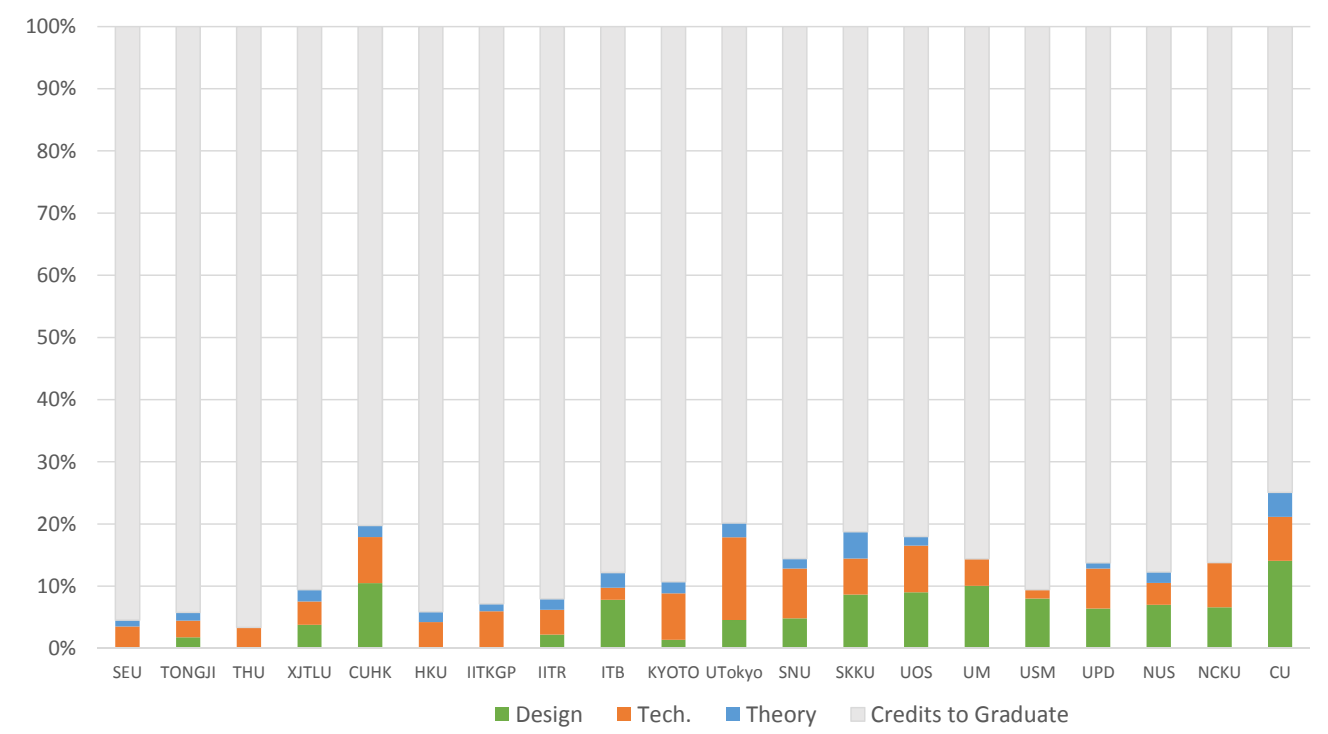

Figure 4. Ratio of required sustainability credits to total graduation credits.

From this perspective we find $\mathrm{CU}$ is the clear champion in sustainability related courses, with nearly $25 \%$ of the total, closely followed by CHUK and U-Tokyo with $20 \%$, and SKKU and UOS in Korea slightly behind. The smallest proportion appears in three of the Chinese schools, both THU and SEU being under 5\%, and Tongji around that value. HKU, IITKGP and IITR are all under 10\%, and the remaining schools vary between $10 \%$ and $15 \%$.

\section{Conclusions}

The present study started as an exploration of Asian schools' curricula, to ascertain their vision and commitment toward sustainable architectural education, identifying and comparing methods and degrees of implementation. The methodology used in the present study has worked very well for objectively analyzing very different curricula, based on published information. The findings from this methodology are very illustrative, uncovering a wealth of diverse attitudes and strategies not apparent in a simple reading of their curricula. While it would be expected that global sustainability problems would have a very similar response in a likewise globalized education, the analysis shows that there are significant differences among countries, and even between schools of the same nationality. For example, while there is some consistency among the three Korean schools (SKKU, UOS and SNU) in rough contents, the latter differs greatly in organization and sequence, providing a completely different educational experience. Another example appears in Hong Kong, where both schools have consistent similarities in dispersed curricula and accumulation of specialized courses in the latter years, but greatly differ, as CUHK is much more organized around design studio integration, and HKU is based on more isolated theory and technology modules.

On the other hand, unexpected similarities occur among schools of different countries. SNU's sequence and composition of subjects is closer to Kyoto than to its Korean counterparts, which instead 
show some similarity with U-Tokyo, although more balanced than the latter. Also remarkable is the fact that in spite of the strict national and even international accreditation systems, schools have much room for designing their own specific programs. Interesting is, for example, the case of schools receiving RIBA accreditation: XJTLU, HKU, CUHK and NUS are under the same umbrella, but their programs are quite diverse, all of them country and school specific.

From examining the general courses contents against the three well-known sustainability areas of ecology, society and economy, we see that the first one clearly receives the most attention. Economic aspects are almost totally absent. In the best of cases there is only a small reference in some courses. This lack makes sustainability education unbalanced, and it would be desirable to implement economics to complete architects' understanding of the whole sustainability problem. Society and culture appear more occasionally, although even in a small number of courses they are extremely important, not only in the study of vernacular typologies and techniques that balance the overdeveloped globalization of design around technology and formal styles, but more interestingly by including traditional philosophies in their teaching and even principles, as we saw with SKKU and IITR.

A positive contribution of the present study is also the importance of the timeline or sequence of courses, identifying at least three strategies currently in use in Asia, which may add further possibilities of personalizing curricula to local and individual circumstances. Continuous, intensive and scattered curricula may have their own advantages depending on the circumstances. Apparently, a continuous curriculum seems most advantageous for a well-integrated and balanced education, as in the case of Kyoto. However, U-Tokyo shows excellent results with its very intensive curriculum, while SKKU and UOS are consolidating their positions as leading schools by implementing a mix of both. The most apparently disadvantageous scattered curriculum method [20] is the basis for schools like CUHK, HKU, USM and UTM, but this does not seem to affect their positive results.

Finally, studio integration is very relevant, as architects cannot completely realize their knowledge or technique unless it is realized within the project process [116]. Some schools like CU are exemplary of an effort to operate in this manner.

Working with 20 schools is not enough for a general conclusion about Asia, but as exploratory research this study elucidates some unexpected facts. Even though we reduced the sample number to 20 , the data we managed is within the limit of what a study of this kind can contain, with the additional difficulty of having to manage information in many different languages. To continue working towards a better vision of the problem, national-level or smaller regional studies are suggested. China or India would need not one but several monographic studies, and a comparison with other regions of Asia and the West will be also another desirable continuation of the present study.

The same methodology can be used, with some fine tuning in the classification of courses (especially elective courses), school selection criteria, and quantitative analysis. Further work is also needed in the development of a graphic tool for assessing curricula in a simple and visual manner, instead of the exclusively literary system used here, in the manner suggested by other studies reviewed [23].

Supplementary Materials: The following is available online at www.mdpi.com/2071-1050/8/3/290/s1, Table S1: Schools and courses matrix.

Acknowledgments: This research was supported by the Basic Science Research Program through the National Research Foundation of Korea (NRF) funded by the Ministry of Science, ICT \& Future Planning (NRF-2014R1A1A1002268). Debapriya Chakrabati, a graduate student of Hongik University, assisted in the collection and interpretation of foreign materials.

Author Contributions: Santiago Porras Álvarez, Kyungsun Lee, and Jiyoung Park contributed equally; Sun-Young Rieh contributed to collecting the data. All authors read and approved the final manuscript.

Conflicts of Interest: The authors declare no conflict of interest. 


\section{Appendix}

Table A1. Relative weight of sustainability-related courses by category \& ratio of required sustainability credits to total graduation credits.

\begin{tabular}{|c|c|c|c|c|c|c|c|c|c|c|c|c|c|c|c|c|c|c|}
\hline & & \multicolumn{8}{|c|}{ Required } & \multicolumn{8}{|c|}{ Elective } & \multirow{3}{*}{$\begin{array}{l}\text { Credits to } \\
\text { Graduate }\end{array}$} \\
\hline & & \multicolumn{4}{|c|}{ No. of Credits } & \multicolumn{4}{|c|}{ Weight (100\%) } & \multicolumn{4}{|c|}{ No. of Credits } & \multicolumn{4}{|c|}{ Weight (100\%) } & \\
\hline & & Design & Tech. & Theory & SUM & Design & Tech. & Theory & SUM & Design & Tech. & Theory & SUM & Design & Tech. & Theory & SUM & \\
\hline \multirow{4}{*}{ China } & SEU & 0.0 & 7.0 & 2.0 & 9.0 & 0.0 & 77.8 & 22.2 & 100.0 & 0.0 & 1.0 & 3.0 & 4.0 & 0.0 & 25.0 & 75.0 & 100.0 & 190 \\
\hline & Tongji & 4.0 & 6.0 & 3.0 & 13.0 & 30.8 & 46.2 & 23.1 & 100.0 & 2.0 & 0.0 & 0.0 & 2.0 & 100.0 & 0.0 & 0.0 & 100.0 & 211.5 \\
\hline & THU & 0.0 & 7.0 & 0.0 & 7.0 & 0.0 & 100.0 & 0.0 & 100.0 & 0.0 & 0.0 & 5.0 & 5.0 & 0.0 & 0.0 & 100.0 & 100.0 & 200 \\
\hline & XJTLU & 10.0 & 10.0 & 5.0 & 25.0 & 40.0 & 40.0 & 20.0 & 100.0 & 0.0 & 0.0 & 0.0 & 0.0 & 0.0 & 0.0 & 0.0 & 0.0 & 200 \\
\hline \multirow{2}{*}{ Hong-Kong } & CUHK & 17.0 & 12.0 & 3.0 & 32.0 & 53.1 & 37.5 & 9.4 & 100.0 & 0.0 & 9.0 & 6.0 & 15.0 & 0.0 & 60.0 & 40.0 & 100.0 & 130 \\
\hline & HKU & 0.0 & 15.0 & 6.0 & 21.0 & 0.0 & 71.4 & 28.6 & 100.0 & 0.0 & 18.0 & 3.0 & 21.0 & 0.0 & 85.7 & 14.3 & 100.0 & 336 \\
\hline \multirow{2}{*}{ India } & IITKGP & 0.0 & 15.0 & 3.0 & 18.0 & 0.0 & 83.3 & 16.7 & 100.0 & 0.0 & 6.0 & 3.0 & 9.0 & 0.0 & 66.7 & 33.3 & 100.0 & 233 \\
\hline & IITR & 5.0 & 9.0 & 4.0 & 18.0 & 27.8 & 50.0 & 22.2 & 100.0 & 0.0 & 3.0 & 6.0 & 9.0 & 0.0 & 33.3 & 66.7 & 100.0 & 208 \\
\hline Indonesia & ITB & 16.0 & 4.0 & 5.0 & 25.0 & 64.0 & 16.0 & 20.0 & 100.0 & 0.0 & 4.0 & 6.0 & 10.0 & 0.0 & 40.0 & 60.0 & 100.0 & 180 \\
\hline \multirow{2}{*}{ Japan } & Kyoto $^{(1)}$ & 2.1 & 11.2 & 2.8 & 16.1 & 13.0 & 69.6 & 17.4 & 100.0 & 3.0 & 2.0 & 2.0 & 7.0 & 42.9 & 28.6 & 28.6 & 100.0 & 134 \\
\hline & U-Tokyo ${ }^{(2)}$ & 4.8 & 14.0 & 2.4 & 21.2 & 22.6 & 66.0 & 11.3 & 100.0 & 0.0 & 0.0 & 0.0 & 0.0 & 0.0 & 0.0 & 0.0 & 0.0 & 84 \\
\hline \multirow{3}{*}{ Korea } & SNU & 9.0 & 15.0 & 3.0 & 27.0 & 33.3 & 55.6 & 11.1 & 100.0 & 0.0 & 0.0 & 9.0 & 9.0 & 0.0 & 0.0 & 100.0 & 100.0 & 160 \\
\hline & SKKU & 18.0 & 12.0 & 9.0 & 39.0 & 46.2 & 30.8 & 23.1 & 100.0 & 0.0 & 3.0 & 0.0 & 3.0 & 0.0 & 100.0 & 0.0 & 100.0 & 169 \\
\hline & UOS & 18.0 & 15.0 & 3.0 & 36.0 & 50.0 & 41.7 & 8.3 & 100.0 & 0.0 & 0.0 & 9.0 & 9.0 & 0.0 & 0.0 & 100.0 & 100.0 & 164 \\
\hline \multirow{2}{*}{ Malaysia } & $\mathrm{UM}$ & 23.0 & 10.0 & 0.0 & 33.0 & 69.7 & 30.3 & 0.0 & 100.0 & 0.0 & 6.0 & 0.0 & 6.0 & 0.0 & 100.0 & 0.0 & 100.0 & 196 \\
\hline & USM & 17.0 & 3.0 & 0.0 & 20.0 & 85.0 & 15.0 & 0.0 & 100.0 & 0.0 & 12.0 & 3.0 & 15.0 & 0.0 & 80.0 & 20.0 & 100.0 & 192 \\
\hline Philippines & UPD & 14.0 & 14.0 & 2.0 & 30.0 & 46.7 & 46.7 & 6.7 & 100.0 & 0.0 & 8.0 & 4.0 & 12.0 & 0.0 & 66.7 & 33.3 & 100.0 & 188 \\
\hline Singapore & NUS & 16.0 & 8.0 & 4.0 & 28.0 & 57.1 & 28.6 & 14.3 & 100.0 & 32.0 & 28.0 & 0.0 & 60.0 & 53.3 & 46.7 & 0.0 & 100.0 & 200 \\
\hline Taiwan & NCKU & 12.0 & 13.0 & 0.0 & 25.0 & 48.0 & 52.0 & 0.0 & 100.0 & 0.0 & 6.0 & 0.0 & 6.0 & 0.0 & 100.0 & 0.0 & 100.0 & 156 \\
\hline Thailand & $\mathrm{CU}$ & 32.0 & 16.0 & 9.0 & 57.0 & 56.1 & 28.1 & 15.8 & 100.0 & 0.0 & 4.0 & 2.0 & 6.0 & 0.0 & 66.7 & 33.3 & 100.0 & 170 \\
\hline $\mathrm{Av}$ & & & & & & 37.3 & 50.3 & 12.4 & 100.0 & & & & & 10.9 & 50.0 & 39.1 & 100.0 & \\
\hline
\end{tabular}

Note: ${ }^{(1)}$ Students must take $70 \%$ of basic major courses, among them the sustainability courses in this table. For the present study, we used a rough approximation by applying a coefficient of 0.7 to the number of credits. ${ }^{(2)}$ All the courses of U-Tokyo in this table belong to the category of "limited elective", which are about $65 \%$ of the whole curriculum (minimum 55 credits out of the total 84). These 55 credits are elected from a total choice of 68 . For the present study, we used a rough approximation by applying a coefficient of $55 / 68 \approx 0.8$ to the number of credits. 


\section{References}

1. East-West Center. The Future of Population in Asia. In Population and Health Studies; East-West Center Research Program: Honolulu, HI, USA, 2002.

2. UN. Population Trends in Asia and the Pacific, United Nations Report. 2002. Available online: http:/ / www.eastwestcenter.org/publications/future-population-asia (accessed on 19 February 2016).

3. Fien, J.; Tilbury, D. The global challenge of Sustainability. In Education and Sustainable Development. Responding to the Global Challenge; Tilbury, D., Stevenson, R.B., Fien, J., Schereuder, D., Eds.; IUCN Commission on Education and Communication: Cambridge, UK, 2002; pp. 1-12.

4. UN Habitat, The State of Asian and Pacific Cities 2015: Urban transformations Shifting from quantity to quality. UN Habitat, London, UK. 2015. Available online: http://unhabitat.org/books/ the-state-of-asian-and-pacific-cities-2015/ (accessed on 18 March 2016).

5. Brundtland, G.; Khalid, M.; Agnelli, S.; Al-Athel, S.; Chidzero, B.; Fadika, L.; Hauff, V.; Lang, I.; Shijun, M.; de Botero, M.M. Our Common Future (Brundtland Report); World Comission on Environment and Development, United Nations, 1987; Avaliable online: http:/ / www.un-documents.net/our-common-future.pdf (accessed on 17 March 2016).

6. Rio Declaration on Environment and Development. United Nations Conference on Environment and Development, Rio de Janeiro, Brazil, 3-14 June 1992. Available online: http://www.unep.org/ documents.multilingual/default.asp?documentid=78\&articleid=1163 (accessed on 17 March 2016).

7. United Nations, Agenda 21. Available online: https://sustainabledevelopment.un.org/outcomedocuments / agenda21 (accessed on 3 February 2016).

8. UNFCCC. United Nations Framework Convention on Climate Change. COP 15. Copenhagen 2009. Available online: http://unfccc.int/meetings/copenhagen_dec_2009/session/6262/php/view /reports.php (accessed on 3 February 2016).

9. Hopkins, C.; McKeown, R. Education for Sustainable Development: An International Perspective. In Education and Sustainable Development. Responding to the Global Challenge; Tilbury, D., Stevenson, R.B., Fien, J., Schereuder, D., Eds.; IUCN Commission on Education and Communication: Cambridge, UK, 2002; pp. 13-26.

10. Malik, A.; Rahman, A. Greening the Architectural Curriculum in All the Malaysian Institutes of Higher Learning-it is not an Option. Int. J. Archit. Res. 2010, 4, 44-53.

11. Kishnani, N. Greening Asia: Emerging Principles for Sustainable Architecture; BCI Asia: Singapore, 2012.

12. Salama, A. Skill-based/Knowledge-based Architectural Pedagogies: An Argument for Creating Humane Environments. In Proceedings of the 7th International Conference of the IAHH-International Association of Humane Habitat-Enlightening Learning Environments, International Association of Humane Habitat-IAHH, Compact Disc, Mumbai, India, 29-31 January 2005.

13. Wright, J. Introducing Sustainability into the Architecture Curriculum in the United States. Int. J. Sustain. High. Educ. 2003, 4, 100-105. [CrossRef]

14. Altomonte, S. Environmental Education for Sustainable Architecture. Rev. Eur. Stud. 2009, 1, $12-21$. [CrossRef]

15. Salama, A.; Amir, A. Paradigmatic Trends in Arab Architectural Education: Impacts and Challenges. In International Union of Architects-UIA XXII World Congress, Istanbul, Turkey, 3-7 July 2005; Available online: http:/ / citeseerx.ist.psu.edu/viewdoc/download?doi=10.1.1.122.8202\&rep=rep1\&type=pdf (accessed on 16 March 2016).

16. Ostwald, M.J.; Williams, A.; Learning, A.; Council, T. Understanding Architectural Education in Australasia; Australian Learning and Teaching Council: Sydney, Australia, 2008.

17. Altomonte, S.; Attia, S.; Herde, A.; Dartevelle, O. EDUCATE State of the Art Academic Curricula and Conditions for Registration; Nottingham University: Nottingham, UK, 2010.

18. Lee, K.Y.D.; Geon, K. A Study on Integrating Sustainability into Architectural Education Curriculum in Korea. J. Archit. Inst. Korea 2012, 28, 127-138.

19. The Homepage of the Australasia Association of Schools of Architecture (AASA). Available online: http:/ / aasa.org.au/schools/ (accessed on 2 February 2016).

20. Karol, E. Using campus concerns about sustainability as an educational opportunity: A case study in architectural design. J. Clean. Prod. 2006, 14, 780-786. [CrossRef] 
21. Knudstrup, M.A.; Eriksen, K.; Petersen, M.D. Education in Sustainable Architecture for the Future-For a Joint Climate Action. In Proceedings of Joint Action on Climate Change Conference, Institut for Samfundsudvikling og Planlægning, Aalborg Universitet, Aalborg, Denmark, 8-10 June 2009; pp. 333-335.

22. Tanuwidjaja, G.; Leonardo, L. Sustainable Architectural Design in Indonesia: Responding the Current Environmental Challenges. J. Ruas 2012, 9, 28-36.

23. Hamiti, S.; Wydler, H. Supporting the Integration of Sustainability into Higher Education Curricula-A Case Study from Switzerland. Sustainability 2014, 6, 3291-3300. [CrossRef]

24. Knight, J.; Morshidi, S. The complexities and challenges of regional education hubs: Focus on Malaysia. High. Educ. 2011, 62, 593-606. [CrossRef]

25. QS Top Universities, Worldwide University Rankings, Guides and Events. Available online: http:/ / www.topuniversities.com/university-rankings (accessed on 14 February 2016).

26. Rauhvargers, A. Global University Rankings and Their Impact-Report II; European University Association asbl: Brussels, Belgium, 2013; p. 86.

27. QS World University Rankings: Methodology. Available online: http://www.topuniversities.com/ university-rankings-articles/world-university-rankings/qs-world-university-rankings-methodology (accessed on 5 February 2016).

28. QS World University Rankings by Subject 2015-Architecture/Built Environment—Asia. Available online: http:/ / www.topuniversities.com/university-rankings/university-subject-rankings/2015/architecture\# sorting=rank+region=71+country $=+$ faculty $=+$ stars=false+search $=($ accessed on 13 February 2016).

29. QS University Rankings: Asia 2015. Available online: http://www.topuniversities.com/university-rankings / asian-university-rankings $/ 2015 \#$ sorting $=$ rank+region $=+$ country $=+$ faculty $=+$ stars $=$ false + search $=($ accessed on 5 February 2016).

30. UIA. UIA Accord on Recommended International Standards of Professionalism in Architectural Practice; UIA Professional Practice Program Joint Secretariat: Durban, South Africa, 2014.

31. NBAA. Universities That Have Passed the Architectural Accreditation, National Board of Architectural Accreditation of China (NBAA). Available online: http://www.canberraaccord.org/ signatoriespublic/China.aspx (accessed on 5 February 2016).

32. The Homepage of Hong Kong Architects Registration Board (ARB). Available online: http:/ /www.arb.org.hk (accessed on 4 February 2016).

33. The Homepage of Hong-Kong Institute of Architects (HKIA). Available online: http://www.hkia.net/en/ Home/Index.htm (accessed on 4 February 2016).

34. The Homepage of Council of Architecture (COA), India. Available online: http://www.coa.gov.in/ (accessed on 10 February 2016).

35. The Homepage of Indonesian Institute of Architects (Ikatan Arksitek Indonesia, IAI). Available online: http:/ / www.iai.or.id (accessed on 13 February 2016).

36. JABEE Category-Dependent Criteria for Accreditation of Professional Education Programs, 2012. Available online: http:/ /www.jabee.org/english (accessed on 4 February 2016).

37. The Homepage of JUAA, Japan University Accreditation Association. Available online: http:/ /juaa.or.jp/en/index.html (accessed on 4 February 2016).

38. Korea Architectural Accrediting Board, KAAB. Conditions \& Procedures for Professional Degree Programs in Architecture, 2013 Edition. Available online: http://www.kaab.or.kr/download/KAAB_2013_C_and_P.pdf (accessed on 11 February 2016).

39. Official Portal Public Service Department of Malaysia (JPA). Available online: http://www.jpa.gov.my (accessed on 13 February 2016).

40. The Homepage of Board of Architects Malaysia (Lembega Arkitekt Malaysia, LAM). Available online: http:/ / www.lam.gov.my (accessed on 13 February 2016).

41. The Homepage of Malayan Institute of Architects (Pertubuhan Akitekt Malaysia, PAM). Available online: http:/ / www.pam.org.my (accessed on 13 February 2016).

42. CHED. Memorandum Order (CMO) No. 61: Series of 2006. Policies, Standards and Guidelines (PSG) for the Bachelor of Science in Architecture. Commission on Higher Education, Republic of the Philippines. Available online: http://www.architectureboard.ph/uploads/1253926997-BS\%20Architecture\%20curriculum.pdf (accessed on 4 February 2016). 
43. Institute of Engineering Education Taiwan, Accreditation Council: Architectural Accreditation Criteria. 27 November 2015. Available online: http://www.ieet.org.tw/InfoTE.aspx?n=AACE (accessed on 4 February 2016).

44. The Homepage of the Royal Institute of British Architects (RIBA). Available online: https://www.architecture.com/RIBA/Home.aspx (accessed on 13 February 2016).

45. The Homepage of the Royal Institution of Chartered Surveyors (RICS). Available online: http://www.rics.org/es/ (accessed on 13 February 2016).

46. The Homepage of the Commonwealth Association of Architects (CAA). Available online: http:/ / www.comarchitect.org (accessed on 13 February 2016).

47. Gibson, R.B. Beyond the pillars: Sustainability assessment as a framework for effective integration of social, economic and ecological considerations in significant decision-making. J. Environ. Assess. Policy Manag. 2006, 8, 259-280. [CrossRef]

48. The Pritzker Prize Homepage. Available online: http://www.pritzkerprize.com (accessed on 14 February 2016).

49. The Homepage of the School of Architecture in Southeast University. Available online: http://arch.seu.edu.cn/home/index.php (accessed on 5 February 2016).

50. Ranking of Architecture Schools in China, China Academic Degrees \& Graduate Education Development Center, Ministry of Education. Available online: http://edu.sina.com.cn/kaoyan/2013-01-29/ 1127370395.shtml (accessed on 16 February 2016).

51. The Homepage of Tsinghua University. Available online: http://www.tsinghua.edu.cn/publish/archen/ education/ (accessed on 3 May 2015).

52. The Homepage of Tongji University Department of Architecture. Available online: http:/ /www.tongji-arch.org/en_introdution.asp (accessed on 3 February 2016).

53. Architectural Curriculum of Xi'an Jiaotong Liverpool University. Available online: http:/ / academic.xjtlu.edu.cn/arch/programmes?menuCode=001 (accessed on 3 February 2016).

54. SEU School of Architecture Curriculum in English. Available online: http://school.cucas.edu.cn/uploads / school/2014/0308/1394257259100915.pdf (accessed on 5 February 2016).

55. The Homepage of the Department of Architecture, Xi'an Jiaotong Liverpool University. Available online: http:/ /academic.xjtlu.edu.cn/arch/SitePages/HomePage.aspx (accessed on 3 February 2016).

56. Xi'an Jiaotong Liverpool University Department of Architecture 2013-2014. Available online: http:/ /academic.xjtlu.edu.cn/arch/SitePages/HomePage.aspx (accessed on 3 February 2016).

57. Xi'an Jiaotong Liverpool University Department of Architecture Master curriculum. Available online: http://www.xjtlu.edu.cn/en/admissions/masters/programmes/952-master-of-architectural-design.html (accessed on 3 February 2016).

58. Tongji University Department of Architecture Curriculum and Syllabus. Available online: http:/ / www.tongii-arch.org/specials_list1.asp (accessed on 3 February 2016).

59. Tongii University Architecture Curriculum. Available online: http://www.doc88.com/p-1896812328481.html (accessed on 14 February 2016).

60. Architecture Curriculum of South East University. Available online: http://www.doc88.com/ p-0032954674714.html (accessed on 14 February 2016).

61. Tsinghua University School of Architecture Syllabus for 2013-2014. Available online: http://www.tsinghua.edu.cn/publish/newthu/newthu_cnt/education/pdf/201402.pdf (accessed on 3 May 2015).

62. Tsinghua University Architecture Undergraduate Program. Available online: http://www.doc88.com/ p-9522398094279.html (accessed on 14 February 2016).

63. HKU. 2013/14 Prospectus, HKU Department of Architecture 2012/ 13 Review; The Department of Architecture, The University of Hong Kong: Hong Kong, China, 2014; p. 144.

64. The Homepage of the School of Architecture, Chinese University of Hong Kong (CUHK). Available online: http:/ / www.arch.cuhk.edu.hk (accessed on 3 May 2015).

65. Lonman, B. School of Architecture. CUHK. 2014-2015. Available online: http://www.arch.cuhk.edu.hk/ v1/index.php/resources/page/publication (accessed on 3 May 2015).

66. The Homepage of Faculty of Architecture, The University of Hong Kong. Available online: http:/ / www.arch.hku.hk (accessed on 10 December 2015). 
67. The Homepage of New Undergraduate Curriculum from 2012. Available online: http:/ /www.cuhk.edu.hk/ 334/english/index-students.html (accessed on 3 May 2015).

68. The Homepage of the Department of Architecture and Planning, Indian Institute of Technology Roorkee. Available online: http://www.iitr.ac.in/departments/AR/pages/About_Us+History.html (accessed on 14 February 2016).

69. The Homepage of Indian Institute of Technology Kharagpur, India. Available online: http://www.iitkgp.ac.in/ (accessed on 10 February 2016).

70. The Homepage of Undergraduate Curriculum. Available online: https://erp.iitkgp.ernet.in/ ERPWebServices/curricula/CurriculaSubjectsList.jsp?stuType=UG\&splCode=AR (accessed on 10 February 2016).

71. Department of Architecture and Planning Curriculum. Available online: http://www.iitr.ac.in/academics / uploads/File/2015/syllabi/UG/AR\%20PDF.pdf (accessed on 14 February 2016).

72. ITB. Institut Teknologi Bandung Undergraduate Student Handbook 2010. Available online: http://www.itb.ac.id/education/ITB_undergraduate_handbook.pdf (accessed on 1 February 2016).

73. Architecture Master Program, Architecture ITB. Available online: http:/ / www.ar.itb.ac.id/master/ (accessed on 13 February 2016).

74. Prospectus 2014, School Of Architecture, Planning \& Policy Development, 2014. Available online: http:/ / sappk.itb.ac.id/upload/FINAL\%20CETAK\%20-\%20SAPPK\%20Prospektus\%20-\%20BUKU\%20Single\% 20Page-1.pdf (accessed on 19 February 2016).

75. The Homepage of the Department of Architecture, University of Tokyo. Available online: http:/ /arch.t.u-tokyo.ac.jp/?lang=en (accessed on 10 February 2016).

76. The Homepage of the Department of Architecture Kyoto University. Available online: http:/ / www.s-ar.t.kyoto-u.ac.jp/en (accessed on 6 February 2016).

77. Department of Architecture Lecture Timetable for Undergraduate. Available online: http:/ /arch.t.u-tokyo.ac.jp/about/activity-1097/ (accessed on 19 February 2016).

78. Architecture Syllabus Kyoto University. Available online: http://www.s-ar.t.kyoto-u.ac.jp/ja/curriculum/ syllabus (accessed on 3 February 2016).

79. The Japan Institute of Architects (JIA), Country Report: Kechikusi Law in Japan. Available online: http://www.jia.or.jp/english/ (accessed on 5 February 2016).

80. Kyoto University Department of Architecture, JABEE Accreditation Documents. Available online: http:/ / www.s-ar.t.kyoto-u.ac.jp/ja/admission/JABEE (accessed on 12 February 2016).

81. Credit Requirements for Graduation, College of Engineering, The University of Tokyo. Available online: http://www.u-tokyo.ac.jp/gen01/reiki_int/reiki_honbun/word/403250021.doc (accessed on 14 February 2016).

82. Architecture Undergraduate Curricula, Kyoto University. Available online: http://www.s-ar.t.kyoto-u.ac.jp/ ja/curriculum/youran (accessed on 6 February 2016).

83. Message from the Dean of the Department of Architecture. Available online: http://arch.t.u-tokyo.ac.jp/ about/message-from-head-of-dept-of-architecture/ (accessed on 19 February 2016).

84. Okada, T. Reform of Holistic Architectural Education in Japan. Architectural Institute of Japan. 2000. Available online: http://www.aij.or.jp/eng/archives/98_00doc/uiappc_c.html (accessed on 16 March 2016).

85. The Homepage of Seoul National University Department of Architecture. Available online: http://architecture.snu.ac.kr/English/ (accessed on 19 February 2016).

86. The Homepage of Sungkyunkwan University Department of Architecture. Available online: http:/ /arch.skku.edu/page/view.php?idx=2 (accessed on 10 February 2016).

87. The Homepage of UOS Architecture. Available online: http://arch.uos.ac.kr/hakbu_eng/architecture/ (accessed on 3 May 2015).

88. UOS Architecture: School Introduction. Available online: http://archi.uos.ac.kr/school/about/ (accessed on 11 February 2016).

89. SNU Department of Architecture Curriculum. Available online: http://architecture.snu.ac.kr/academics/ curriculum_2016.php (accessed on 17 March 2016).

90. SNU Portal of Course Registration System. Available online: http://sugang.snu.ac.kr (accessed on 10 February 2016). 
91. SKKU Department of Architecture Curriculum. Available online: http://www.skku.edu/eng_home/edu / hu_science/curriculum_info.jsp?gCode=316307\&pageId=655\&imgTitleId=p000081 (accessed on 10 February 2016).

92. Department of Architecture, Sungkyunkwan University. Architecture Program Report (APR); Department of Architecture, Sungkyunkwan University: Suwon, Korea, 2012.

93. Rieh, S.-Y. Teaching Sustainable Architecture: Holistic Approach for a Sustainable Design Studio. In Proceedings of the International Symposium on Architectural Interchanges in Asia (ISAIA), Gwang-Ju, Korea, 22-25 October 2012.

94. The Homepage of the School of Housing, Building and Planning, Universiti Sains Malaysia. Available online: http:/ /hbp.usm.my/index.php/ms/ (accessed on 14 February 2016).

95. Universiti Sains Malaysia, Bachelor of Architecture, Academic Session 2014/2015. Available online: https://www.usm.my/images/pdf_ijazah/1314hbp.pdf (accessed on 14 February 2016).

96. Faculty of Built Environment, Academic Guidebook Academic Year 2013/2014. Universiti Teknologi Malaysia. Available online: http://fab.utm.my/wp-content/uploads/2015/08/ FabGuideBook2013-2014_FINAL.pdf (accessed on 14 February 2016).

97. The Homepage of Universiti Teknologi Malaysia Department of Architecture. Available online: http:/ / fab.utm.my/departments-institutes/architecture/ (accessed on 14 February 2016).

98. UTM. Academic Guidebook Academic Year 2013/2014; Faculty of Built Environment, Univeristi Teknologi Malaysia: Johor, Malaysia, 2013.

99. The Homepage of the College of Architecture, University of the Philippines Diliman. Available online: http:/ / upca.upd.edu.ph (accessed on 4 February 2016).

100. UPD MsArch Curriculum. Available online: http://upca.upd.edu.ph/uploads/1/8/5/4/18549486/ bs_architecture_2012.pdf (accessed on 1 February 2016).

101. UPD MsArch Course Description. Available online: http://upca.upd.edu.ph/uploads/1/8/5/4/18549486/ bs_arch_2012_course_desc.pdf (accessed on 1 February 2016).

102. The Homepage of the Department of Architecture, National University of Singapore (NUS). Available online: http:/ / www.arch.nus.edu.sg/about-us/about-us.html (accessed on 11 February 2016).

103. NUS Architecture BA Course Information. Available online: http:/ /www.comp.nus.edu.sg/ junzhi/registrar/ SDE/UG/UGedu.html (accessed on 3 May 2015).

104. NUS Centralized Online Undergraduates Registration System (CORS). Available online: http:/ / www.cors.nus.edu.sg/ (accessed on 16 February 2016).

105. NUS Learning Management System. Available online: https://ivle.nus.edu.sg/V1/lms/public/ view_moduleoutline.aspx?CourseID=B18E5999-3C47-41FC-9DFF-CA91F634983F\&ClickFrom=StuViewBtn (accessed on 16 February 2016).

106. NUS Course Information. Available online: https://ivle.nus.edu.sg/lms/public/list_course_public.aspx? (accessed on 3 May 2015).

107. NUS Architecture MArch Course Information. Available online: https://www.arch.nus.edu.sg/programme/ architecture/m-arch/master_dtm_info.html (accessed on 26 February 2016).

108. AD Architecture School Guide: National University of Singapore. Available online: http:/ / www.archdaily.com/462070/ad-architecture-school-guide-national-university-of-singapore/ (accessed on 3 May 2015).

109. Marginson, S.; van der Wende, M. Globalization and Higher Education; OECD Education Working Papers, No. 8; OECD Publishing (NJ1): Paris, France, 2007.

110. The Homepage of National Cheng Kung University (NCKU) Department of Architecture. Available online: http:/ / www.arch.ncku.edu.tw/en (accessed on 3 February 2016).

111. Department of Architecture National Cheng Kung University Curricula. Available online: http://www.arch.ncku.edu.tw/content/課程 (accessed on 18 March 2016).

112. National Cheng Kung University Course Catalog. Available online: http://class-qry.acad.ncku.edu.tw/ qry/index.php (accessed on 12 February 2016).

113. The Homepage of the Department of Architecture, Chulalongkorn University. Available online: http://www.archdept.com/web/index.php (accessed on 4 February 2016).

114. Information: Department of Architecture Chulalongkorn University. Available online: http:/ /www.archdept.com/web/information.php (accessed on 19 February 2016). 
115. Department of Architecture 2014 Yearbook, Chulalongkorn University. Available online: http://www.archdept.com/web/showcase_detail19.php (accessed on 4 February 2016).

116. Kishnani, N.; Ng, L.J. Educating the architect; formation of sustainability constructs. In Proceedings of the Sustainable Buildings Conference, Helsinki, Finland, 18-21 October 2011.

(c) 2016 by the authors; licensee MDPI, Basel, Switzerland. This article is an open access article distributed under the terms and conditions of the Creative Commons by Attribution (CC-BY) license (http:/ / creativecommons.org/licenses/by/4.0/). 